\title{
Remagnetization mechanisms in Triassic red beds from South China
}

2

\author{
Zhaoxia Jiang $^{\text {a, b, c }}$, Qingsong Liu ${ }^{\text {b,d }}$, Mark J. Dekkers ${ }^{\mathrm{e}}$, Xiang Zhao ${ }^{\mathrm{c}}$, \\ Andrew P. Roberts ${ }^{\mathrm{c}}$, Zhenyu Yang ${ }^{\mathrm{f}}$, Chunsheng Jin ${ }^{\mathrm{a}}$, and Jianxing Liu ${ }^{\mathrm{g}, \mathrm{b}}$
}

${ }^{\mathrm{a}}$ State Key Laboratory of Lithospheric Evolution, Institute of Geology and Geophysics, Chinese Academy of Sciences, Beijing 100029, P.R. China

${ }^{\mathrm{b}}$ Laboratory for Marine Geology, Qingdao National Oceanography Laboratory for Marine Science and Technology, Qingdao 266061, P.R. China

${ }^{c}$ Research School of Earth Sciences, Australian National University, Canberra, ACT 2601, Australia

${ }^{\mathrm{d}}$ South University of Science \& Technology, Shenzhen, 518055, P.R. China

${ }^{\mathrm{e}}$ Department of Earth Sciences, Faculty of Geosciences, Utrecht University, Budapestlaan 17, 3584 CD Utrecht, The Netherlands

${ }^{\mathrm{f}}$ College of Resource Environment and Tourism, Capital Normal University, Beijing, 100048, P.R. China

${ }^{\mathrm{g}}$ Key Laboratory of Marine Sedimentology and Environmental Geology, First Institute of Oceanography, State Oceanic Administration, Qingdao, 266061, P.R. China

*Corresponding author: Qingsong Liu (liux0272@yahoo.com) 
Abstract

Paleogeographic reconstructions based on paleomagnetic data rely on the reliability of the natural remanent magnetization $(\mathrm{NRM})$ as a primary geomagnetic signal.

Remagnetizations, however, can be common in many rock types, including late Paleozoic and Mesozoic red beds, and they complicate paleogeographic interpretations. Extracting the primary NRM from partially remagnetized rocks, and understanding the remagnetization mechanism are important in these contexts. We carried out a systematic paleomagnetic study of red bed samples from the Triassic Huangmaqing Formation, Nanjing $\left(32.0^{\circ} \mathrm{N}, 118.9^{\circ} \mathrm{E}\right)$, South China. Two NRM components carried by secondary and primary hematite are isolated in 47 of the 94 samples studied, where the latter component has a direction in stratigraphic coordinates of $D=29.2^{\circ}, I=34.6^{\circ}\left(\alpha_{95}=10.9^{\circ}, 47\right.$ samples from 6 sites $)$ that yields a paleopole of $\lambda=60.8^{\circ} \mathrm{N}, \phi=228.1^{\circ} \mathrm{E}, d p / d m=12.5 / 7.2$, which is consistent with Triassic pole positions for the South China Block. A secondary chemical remanent magnetization $(\mathrm{CRM})\left(D=227.1^{\circ}, I=80.8^{\circ}, \alpha_{95}=7.3^{\circ}\right)$ is documented in all 94 samples from 10 sites and is carried by pigmentary hematite that is inferred to have been generated by magnetite oxidation during orogenic activity. This secondary component has steep inclinations and is interpreted to have been influenced by a combination of the remanence carried by original parent magnetite, the orogenic stress field, and the prevailing geomagnetic field direction during deformation. This CRM direction is recorded commonly by red beds from the South China Block, and is significant for regional tectonic studies in the area.

Keywords: remagnetization, red beds, hematite, chemical remanent magnetization, detrital remanent magnetization, South China Block, Triassic 


\section{Introduction}

Remagnetization, a phenomenon by which a natural remanent magnetization (NRM) is acquired in an ambient magnetic field of a much younger age than that of the rock or sediment itself, complicates interpretation of paleomagnetic data from rocks, soils, and sediments (McCabe and Elmore, 1989; Suk et al., 1993; Lu et al., 1994; Piper et al., 1999; Roberts and Weaver, 2005; Rowan and Roberts, 2006; Deng et al., 2007; Jin and Liu, 2011; Liu et al., 2011; van der Voo and Torsvik, 2012; Roberts, 2015). Generally, remagnetization mechanisms involve several pathways, 1) mineral transformations associated with redox process, i.e. magnetite, greigite, or pyrrhotite formation (Katz et al., 2000; Weaver et al., 2002; Roberts and Weaver, 2005), 2) deformation-associated fluid migration and/or pressure solution (McCabe and Elmore, 1989; Elmore and McCabe, 1991; Housen et al., 1993), 3) chemical weathering in moist, tropical weathering, and soil-forming environments (Creer, 1961, 1968; Jin and Liu, 2011; Liu et al., 2011), or 4) thermoviscous remanent magnetization acquisition (Scotese et al., 1982; Kent, 1985; Hashimoto et al., 2008; Globokar, 2014). Acquisition of secondary magnetizations through any such mechanism will obscure the primary paleomagnetic record (McCabe and Elmore, 1989; van der Voo and Torsvik, 2012), and may lead to inaccurate paleomagnetic interpretations if not recognized (McCabe and Elmore, 1989; van der Voo and Torsvik, 2012; Dekkers, 2012).

In the South China Block (SCB), widely distributed late Paleozoic and Mesozoic red beds have been subjected to extensive paleomagnetic investigations, aimed at reconstructing regional paleogeography (e.g. Achache et al., 1984; Zaman and Torii, 1999; Steiner and Lucas, 2000; Sun et al., 2006). However, the reliability of the NRM recorded by red sediments is often questioned because widespread and largely pervasive remagnetizations have been documented (Dobson and Heller, 1992; Wang and van der Voo, 1993; Huang and 
Opdyke, 1996; Liu et al., 2011). The prevalent remagnetization scenario is considered to be some form of chemical remanent magnetization (CRM) acquired long after deposition (McCabe and Elmore, 1989; Elmore et al., 2012; van der Voo and Torsvik, 2012). The most frequently occurring CRM carrier in red beds is hematite pigment, which can overprint a detrital remanent magnetization (DRM) carried by primary hematite. Therefore, discrimination of a CRM from a DRM is central to paleomagnetic studies of red beds. Hematites from different environments have distinct morphologies, crystallinity ranges, and magnetic properties (Collinson, 1965; Walker et al., 1981; Sugimoto et al., 1993, 1998; Jiang et al., 2012, 2014), which can be used to distinguish the origin of the hematite under investigation.

Thermal demagnetization (TD) is the most popular method for identifying a DRM or $\mathrm{CRM}$ in red beds due to their different unblocking temperature spectra (McClelland-Brown, 1982; Iosifidi et al., 2010; Jiang et al., 2015). Detrital hematite has a narrow unblocking temperature spectrum at the highest temperatures $\left(\sim 660-680^{\circ} \mathrm{C}\right)$ because it usually occurs as stable single domain (SD) particles with often close to ideal stoichiometry. Pigmentary hematite is typically finer-grained with sizes closer to the superparamagnetic (SP) to SD threshold size, so that it has a much broader unblocking temperature spectrum at lower temperatures $\left(300-650^{\circ} \mathrm{C}\right)$ (Stokking and Tauxe, 1990a; Jiang et al., 2015). Alternating field demagnetization (AFD) is also important in paleomagnetic studies, but it is not particularly effective for treating red beds because hematite has high coercivities (Butler, 1992; Dunlop and Özdemir, 1997). Chemical demagnetization (CD) has been used only occasionally for analyzing red sediments with multiple NRM components within a single sample (Burek, 1969; Collinson, 1975; Kent and Opdyke, 1978; Henry, 1979; Tauxe et al., 1980; Tan et al., 2007). Most rocks contain a relatively large number of remanence-carrying grains that have variable chemical and physical properties. Ideally, the remanence in certain grains will be 
effectively removed by chemical dissolution during $\mathrm{CD}$, whereas in others it will remain unchanged. As the level of demagnetization (i.e. hematite dissolution) increases, the number of grains affected also increases (Larson, 1981). Grains that are more likely to acquire secondary magnetic components are more susceptible to lower levels of demagnetization. The fine-grained hematite pigment will dissolve first, leaving behind partially dissolved coarser specularite grains (Henry, 1979; Tauxe et al., 1980; Tan et al., 2007). This would allow identification of the NRM component carried by detrital specularite.

For remagnetized red beds, it is difficult to isolate the characteristic remanent magnetization (ChRM) and to establish it as the primary NRM component, especially in pervasively remagnetized red beds. The relative effectiveness of the various demagnetization techniques for identifying the advantages and disadvantages of each method has yet to be tested widely for remagnetized red beds. Therefore, in this study, we carried out systematic TD, CD, and combined $\mathrm{CD}-\mathrm{TD}$, with associated rock magnetic analysis, on 94 remagnetized red bed samples to assess their efficacy for paleomagnetic analysis of remagnetized red bed samples and to investigate the mechanisms by which remagnetization occurred.

\section{Sampling and measurements}

\subsection{Sampling}

The Middle Triassic Huangmaqing Formation is investigated here. A total of 94 standard paleomagnetic cores (10 sites) with $25-\mathrm{mm}$ diameter, were collected in a transect from the village of Xiawuqi to Zijinshan Hill to the northeast of Nanjing, South China $\left(32.0^{\circ} \mathrm{N}, 118.9^{\circ} \mathrm{E}\right)$ (Figure 1a). The Huangmaqing Formation consists of clastic rocks, including purplish-red siltstones and fine sandstones (Figure 1b). The beds dip shallowly to the south $\left(7-22^{\circ}\right)$. Paleomagnetic samples were cored with a portable drill and were oriented 
magnetically. Core samples were cut into three cylindrical sister-specimens $1-\mathrm{cm}$ in length in the laboratory for TD, combined CD-TD treatment on NRM, and combined CD-TD treatment on three-orthogonal isothermal remanent magnetization (IRM) components (Lowrie, 1990). Fresh off-cuts that remained after cutting specimens were used for other rock magnetic measurements.

\subsection{Paleomagnetic measurements}

One set of sister-specimens (94 samples) was subjected to stepwise TD measurements in 33 steps up to $695{ }^{\circ} \mathrm{C}$ at $50{ }^{\circ} \mathrm{C}$ intervals from 20 to $600{ }^{\circ} \mathrm{C}$ and at $5{ }^{\circ} \mathrm{C}$ intervals from 600 to $695{ }^{\circ} \mathrm{C}$ using a thermal demagnetizer (PGL-100) developed at the Paleomagnetism and Geochronology Laboratory (PGL), Institute of Geology and Geophysics, Chinese Academy of Sciences, Beijing, China, in a magnetically shielded room. Remanent magnetizations after each TD step were measured with a 2-G Enterprises RAPID three-axis magnetometer (Kirschvink et al., 2008).

A second set of sister-specimens was subjected to combined CD-TD treatment. First, specimens were subjected to chemical leaching experiments. To increase the surface area of samples for more pervasive acid percolation, $0.5-\mathrm{mm}$ diameter holes were drilled into each side of the cylinders (Figure 1c). CD was carried out using $8 \mathrm{~N}$ (normality) hydrochloric acid $(\mathrm{HCl})$. Specimens from each site were soaked in a plastic bottle with $100 \mathrm{ml}$ of acid. The specimen bottles were placed in a magnetically shielded space, where the ambient field was kept constant $(<200 \mathrm{nT})$ within a set of Helmholtz coils. Initially, specimens were measured magnetically after every three hours of leaching. Specimens were washed with distilled water at each step, and were dried in a furnace at $40^{\circ} \mathrm{C}$ in a magnetically shielded space before measuring the remaining NRM to prevent the wet specimens and still slightly acidic leachate from damaging the magnetometer. After each measurement the specimens 
were re-soaked in fresh acid $(100 \mathrm{ml}$ each time). After the first three steps, samples were soaked in acid for 24 hours at each step. When the remanence became stable at $\sim 20 \%$ of the initial NRM on further demagnetization, the leaching process was considered complete. Fourteen chemical leaching steps were performed, with three steps of 3-hour soakings and eleven steps of 24-hour soakings. Afterward, the samples were subjected to a cycle of TD measurements to remove the remaining NRM.

\subsection{Rock magnetic measurements}

To investigate the magnetic mineralogy, hysteresis loops for 40 representative samples from all sites (4 samples from each site) were measured to a maximum field of $1 \mathrm{~T}$ using a Princeton Measurements Corporation vibrating sample magnetometer (MicroMag VSM 3900), from which the coervicity $\left(B_{\mathrm{c}}\right)$, saturation remanent magnetization $\left(M_{\mathrm{r}}\right)$, and saturation magnetization $\left(M_{\mathrm{s}}\right)$ were determined. Isothermal remanent magnetization (IRM) acquisition curves and back-field demagnetization curves were measured for the same samples to determine the coercivity of remanence $\left(B_{\mathrm{cr}}\right)$. First derivatives of IRM acquisition curves were fitted with coercivity components following Kruiver et al. (2001) and Heslop et al. (2002). For further magnetic mineralogy analyses, the temperature dependence of magnetization (M-T) was measured in a steady $1 \mathrm{~T}$ field from room temperature to $800{ }^{\circ} \mathrm{C}$ in air with a Magnetic Measurements variable field translation balance (VFTB). Zero-field cooled (ZFC) warming curves were measured with a Quantum Design Magnetic Properties Measurement System (MPMS XP-5, sensitivity $5.0 \times 10^{-10} \mathrm{Am}^{2}$ ) for samples before and after total CD treatment to detect changes in magnetic mineralogy. Samples were first cooled from room temperature to $15 \mathrm{~K}$ in zero-field and were then exposed to a field of $5 \mathrm{~T}$ (this IRM is denoted as IRM $M_{5}$ ). After the magnetic field was switched off, IRM $\mathrm{IR}_{5 \mathrm{~T}}$ was measured from 15 to $300 \mathrm{~K}$ at $2.5 \mathrm{~K}$ intervals. 
A final set of sister specimens was used for stepwise CD-TD measurements of a three-component IRM following the procedure of Lowrie (1990) to monitor the leaching and thermal behaviour of the different coercivity components. First, samples were magnetized in successively smaller fields along three mutually perpendicular sample axes (2.5 $\mathrm{T}$ along the $\mathrm{z}$-axis, $0.5 \mathrm{~T}$ along the $\mathrm{y}$-axis, and $0.05 \mathrm{~T}$ along the $\mathrm{x}$-axis, respectively). The samples were then subjected to CD-TD measurements following the same procedure as for the second group of sister-specimens in the NRM demagnetization process.

To measure magnetic property variations during $\mathrm{CD}$, fresh offcut samples were also subjected to 14 steps of stepwise chemical leaching in the same batch as the oriented samples for NRM demagnetization. Hysteresis loops and IRM acquisition curves were measured after each leaching step. This is the first study in which rock magnetic properties of red beds have been monitored during chemical leaching.

\section{Results}

\subsection{Paleo- and rock magnetic characterization of red bed samples}

Typical NRM intensities for the studied specimens are about $10^{-2} \mathrm{~A} / \mathrm{m}$. Based on TD results, samples can be divided into three groups. Samples from individual sites have similar demagnetization behaviour, i.e. most samples are allocated to the same group. Group I samples ( $\sim 39$ specimens/4 sites) have relatively straightforward demagnetization behaviour characterized by a single linear trajectory between 100 and $660{ }^{\circ} \mathrm{C}$ (Figure 2a-1). This indicates that hematite is a significant ChRM carrier. The magnetization direction is oriented to the northwest with moderate to steep-downward-directed inclinations in in-situ coordinates. Directions for each site before and after tilt correction are summarized in Table 1. They differ from the present-day geomagnetic field direction before bedding correction. M-T curves decrease gradually during heating and reach zero at $\sim 670{ }^{\circ} \mathrm{C}$, which further 
indicates that hematite is the dominant magnetic mineral (Figure 2a-4). A bulk coercivity $\boldsymbol{B}_{\mathbf{c}}$ of $342 \mathrm{mT}$ was determined from the hysteresis loop after slope correction between 0.9 and $1 \mathrm{~T}$ (Figure 2a-2). This $\boldsymbol{B}_{\mathrm{c}}$ value should be considered as a lower bound since it is based on a minor hysteresis loop: the maximum available applied field of $1 \mathrm{~T}$ is insufficient to saturate the samples at room temperature magnetically. However, IRM component analysis indicates that two coercivity components can be identified, a dominant component with median acquisition field $\left(B_{\mathrm{H} 1 / 2}\right)$ of $600-630 \mathrm{mT}$ that contributes $90 \%$ of the IRM and a small component $(10 \%)$ with median acquisition field $\left(B_{\mathrm{L} 1 / 2}\right)$ of $\sim 100 \mathrm{mT}$ (Figure 2a-3).

In Group II samples ( 14 specimens/2 sites), two NRM components are identified from TD analysis (Figure 2b-1). Component $\mathrm{A}$ (Comp A) is isolated below $670{ }^{\circ} \mathrm{C}$, and accounts for $70-80 \%$ of the initial NRM intensity. It is northwest-directed with a steep positive inclination, close to the direction of Group I samples, which is distinct from the present-day geomagnetic field direction. A second component, designated as component B (Comp B), is resolved between 670 and $690{ }^{\circ} \mathrm{C}$ with 5 demagnetization steps and is directed to the northwest with a shallow negative inclination in geographic coordinates. M-T curves decay gradually to $670{ }^{\circ} \mathrm{C}$ and then drop to zero abruptly at $\sim 685{ }^{\circ} \mathrm{C}$, which is consistent with the NRM TD results (Figure $2 \mathrm{~b}-4$ ). Bulk $B_{\mathrm{c}}$ for a representative sample is $\sim 398 \mathrm{mT}$, again a lower bound value derived from an unsaturated hysteresis loop (Figure 2b-2), with two coercivity components identified from IRM analysis with $B_{\mathrm{H} 1 / 2}$ of $700-710 \mathrm{mT}$ (i.e. higher than that of Group I) and $B_{\mathrm{L} 1 / 2}$ of $\sim 200 \mathrm{mT}$ (Figure 2b-3) (higher than that of Group I).

Group III samples ( $\sim 33$ specimens/4 sites) also have two magnetic components, where Comp A dominates up to $670{ }^{\circ} \mathrm{C}$ with a northeast direction and steep downward-directed inclination in situ, and Comp B (based on 5 demagnetization levels) is resolved from 670 to $690{ }^{\circ} \mathrm{C}$ with a northeast direction and shallow positive inclination (Figure 2c-1). M-T 
curves of Group III samples are similar to those of Group II samples, with magnetic ordering temperatures of $\sim 685{ }^{\circ} \mathrm{C}$ (Figure 2c-4). The bulk $B_{\mathrm{c}}$ for representative Group III samples is $\sim 230 \mathrm{mT}$ (Figure 2c-2), and IRM acquisition curves can be fitted with two components with $B_{\mathrm{H} 1 / 2}$ of $\sim 430 \mathrm{mT}$ and $B_{\mathrm{L} 1 / 2}$ of $\sim 60-65 \mathrm{mT}$ (Figure 2c-3), both lower than the equivalent fractions in Groups I and II.

The model of Jiang et al. (2015) was used to analyze NRM TD curves for the three sample groups to assess whether the NRM is a CRM or a DRM. This model was developed mainly for red bed samples, and discriminates between two types of hematite, specular grains and red pigment, which are known to occur in red beds. The former have coarser grain sizes and record a DRM and fine-grained pigment records a CRM. Blocking temperature is related positively to particle size in the stable SD state based on Néel theory (Dunlop and Özdemir, 1997), hence the maximum unblocking temperature of DRM is higher than that of CRM. Also, based on the results of Jiang et al. (2015) and references therein, DRM and CRM decay curves have different shapes. Therefore, these distinct differences may be used to distinguish CRM from (most of the) DRM in red beds. Although the unblocking temperature spectra of CRM recorded by coarse particles will overlap with that of DRM and complicate their distinction as NRM components, this method can be useful as a secondary, supporting line of evidence to discriminate CRM and DRM in red beds. Curves for Group I samples have a concave shape and decay to zero gradually, which is consistent with expected CRM behaviour (Figure 3a). Samples from the other two groups have curves with similar shapes to those expected for a DRM, with abrupt decreases to zero at $\sim 670-690{ }^{\circ} \mathrm{C}$ (Figure $3 b$ ). Based on TD and rock magnetic results, Group I samples are interpreted to have been completely remagnetized by a CRM, while samples from the other two groups are partially remagnetized and record a mixture of a CRM and a DRM. 


\subsection{Rock magnetic monitoring of CD-TD behaviour of red bed samples}

To monitor the CD-TD behaviour of different coercivity components, stepwise CD-TD treatment of a three-component IRM was carried out on a series of sister specimens. Before $\mathrm{CD}$ treatment, the medium $(50-500 \mathrm{mT})$ and hard $(>500 \mathrm{mT})$ components are dominant (Figure 4a-c). During stepwise CD treatment, the IRM decreases sharply to become constant after six steps for Group I samples (Figure 4a), while for the other two sample groups, the IRM is more resistant to CD treatment and ceases to decrease further after 12 and 8 steps, respectively (Figure 4b, c). During subsequent TD treatment, the medium coercivity component is dominant. The soft component for all samples is unblocked below $\sim 600{ }^{\circ} \mathrm{C}$, while the medium and hard components are completely unblocked at $\sim 680{ }^{\circ} \mathrm{C}$. In addition, a weak Verwey transition is detected in low-temperature ZFC curves (Figure 5a-c), which indicates that magnetite occurs in the samples. For samples after 14-step CD treatment, an obvious Verwey transition is observed but the IRM intensity has decreased to $10 \%$ of that before $\mathrm{CD}$ treatment (Figure $5 \mathrm{~d}-\mathrm{f}$ ). We infer that the expression due to magnetite may be concealed by massive amounts of hematite in the non-leached samples. After CD treatment, hematite pigment is dissolved, so magnetite can be detected more easily with magnetic methods, which supports the notion that pigmentary hematite is dissolved preferentially, and that detrital magnetite is more difficult to dissolve (Hu et al., 2013). Therefore, we conclude that magnetite is responsible for the soft IRM component and that hematite is responsible for the latter two components.

IRM acquisition curves after each CD leaching step were determined for 52 samples. Two coercivity components can be identified from the IRM acquisition curves, a dominant component with high coercivity of $B_{\mathrm{H} 1 / 2}$ and a soft component with coercivity of $B_{\mathrm{L} 1 / 2}$ (representative examples are shown in Figure $4 \mathrm{~d}-\mathrm{f}$ and Table 2). $B_{\mathrm{H} 1 / 2}$ and $B_{\mathrm{L} 1 / 2}$ decrease 
during progressive $\mathrm{CD}$ treatment for samples from the three identified groups. For Group I samples (13 specimens), $B_{\mathrm{H} 1 / 2}$ decreases from $\sim 800 \mathrm{mT}$ to $\sim 100 \mathrm{mT}$, while $B_{\mathrm{L} 1 / 2}$ decreases from $\sim 80 \mathrm{mT}$ to $\sim 20 \mathrm{mT}$ (Figure $4 \mathrm{~d}$ ), which leads to a decreasing bulk $B_{\mathrm{cr}}$. It also suggests that both the "hard" and "soft" components are attacked by the acid, so that coarse and fine particles become finer or are dissolved completely. For sample groups II and III, coercivity variations during CD treatment are not as marked as for Group I samples (Figure 4d-f). For Group II samples (6 specimens), $B_{\mathrm{H} 1 / 2}$ decreases from $\sim 700$ to $\sim 400 \mathrm{mT}$, and $B_{\mathrm{L} 1 / 2}$ decreases from $\sim 200$ to $\sim 40 \mathrm{mT}$ (Figure $4 \mathrm{e}$ ), while for Group III samples (33 specimens), $B_{\mathrm{H} 1 / 2}$ decreases from $\sim 500$ to $\sim 200 \mathrm{mT}$, and $B_{\mathrm{L} 1 / 2}$ decreases from $\sim 60$ to $\sim 20 \mathrm{mT}$ (Figure $4 \mathrm{f}$ ). Based on the three-component IRM features (Figure 4a-c) and low temperature results (Figure 5), the low coercivity component with $B_{\mathrm{L} 1 / 2}$ around $20 \mathrm{mT}$ is interpreted to be magnetite.

\subsection{Comparison of chemical and thermal demagnetization results}

For Group I samples, the primary NRM is difficult to identify with TD because it is overprinted completely by a secondary CRM. However, a potentially meaningful ChRM component can be identified from TD results for Groups II and III. Group I samples have a brighter red colour and seem to be more pigmented than the others which could explain the absence of a primary ChRM. This raises the question of whether CD is more effective in isolating a ChRM in red beds, and whether it can resolve a ChRM for Group I.

TD only (referred to as 'direct TD'), CD, and combined CD-TD results are summarized in Figure 6. Group I samples have a single linear trajectory in both CD and TD; TD applied after completion of $\mathrm{CD}$ also reveals the same trajectory (Figure 6a). In equal-area projections, demagnetization trajectories for TD and CD-TD overlap (Figure 6b). For stepwise CD and TD, about half of the NRM was demagnetized by CD (Figure 6c), with CD 
causing bleaching of the initially red samples (Figure 1c, d). For Group II samples, direct TD and combined CD-TD yield contrasting results. A primary reversed polarity direction was extracted from direct TD, while for the stepwise CD-TD protocol, two components are identified. One component is similar to Comp A identified in the direct TD protocol, while the direction for the latter is almost a vector combination of the two components extracted from direct TD measurements (Figure 6d, e). Only 10\% of the NRM is left after CD (Figure 6f). For Group III samples, CD-TD reveals two components, which are essentially parallel to the two components identified from direct TD treatment (Figure $6 \mathrm{~g}$ ), with almost $85 \%$ of the NRM removed by CD.

\section{Discussion}

\subsection{Comparison of the effectiveness of thermal and chemical demagnetization}

TD results allow identification of two components (Comps A and B) in samples from Groups II and III (6 sites), while only Comp A can be distinguished in samples from Group I (4 sites). Site mean directions (Fisher, 1953) are presented in Figure 7 and Table 1. The formation site-averaged direction for Comp A for all three groups is $D=355.1^{\circ}, I=80.5^{\circ}$ $\left(\mathrm{N}=10, \kappa=35.9, \alpha_{95}=7.3^{\circ}\right)$ (Figure 7a). Directions for Comp B fall into two groups, one with positive inclinations with a formation mean direction of $D / I=29.3^{\circ} / 16.8^{\circ}(\mathrm{N}=4, \kappa=$ $\left.35.7, \alpha_{95}=10.9^{\circ}\right)$, and the other with negative inclinations $\left(D / I=229.9^{\circ} /-12.8^{\circ}, \mathrm{N}=2, \kappa=\right.$ 45, $\alpha_{95}=10.1^{\circ}$ ), which is consistent with previous results from this area (Opdyke et al., 1986; Su et al., 2005) (Figure 7b). Comp B directions pass a reversals test at the 95\% significance level (McFadden and McElhinny, 1990). Although we cannot conduct a fold test because the sampled Huangmaqing Formation red beds are monoclinal, the tilt test (Watson and Enkin, 1993; Enkin, 2003) for Comp B gives a maximum grouping of directions at 144 percent untilting (Figure S1). All of these observations indicate that Comp 
$\mathrm{B}$ has a pre-folding origin. Thus, thermal demagnetization is effective for analyzing partially remagnetized red beds with dispersed unblocking temperature spectra. The direction obtained from CD treatment is similar to that identified from TD for Comp A with steep downward-directed inclinations (Figure 7c); however, Comp B cannot be isolated from combined CD-TD treatment (Figure 7d). Our results indicate that TD is more effective than $\mathrm{CD}$, which raises the question of why $\mathrm{CD}$ is less effective in these samples.

Red bed NRMs are generally a composite of a DRM and CRM, where the former is often thought to be carried by relatively coarse detrital magnetic minerals (i.e. hematite or magnetite), while the latter is recorded by fine-grained hematite pigment (e.g. Collinson, 1974; Larson and Walker, 1975; McClelland, 1996; Iosifidi et al., 2010). Fine-grained hematite pigment is expected to be more soluble than coarser detrital hematite particles. $\mathrm{HCl}$ leaches all iron oxides, and removes the most soluble grains first leaving less soluble grains behind (Burek, 1969; Park, 1970; Henry, 1979; Tauxe et al., 1980). For example, fine-grained hematite cement has a propensity to dissolve and, therefore, dissolves readily, leaving behind partially dissolved specularite (Henry, 1979; Cornell and Giovanoli, 1993). This allows identification of the magnetization component carried by detrital specularite. Therefore, CD could be useful when dealing with sediments with multicomponent magnetizations within a single sample, such as a DRM and CRM. However, if the solubility spectra of hematite cement and specularite overlap in some unknown fashion, simple vector subtraction cannot be used to identify the respective components.

IRM unmixing analysis indicates that low- $(\sim 100-200 \mathrm{mT})$ and high-coercivity ( 500-700 mT) components can be separated (Figure 2), which may reflect different particle size distributions of hematite based on the positive relationship of particle size and coercivity. During acid leaching, the coercivities of the two components decrease simultaneously (Figure 4e-f), which indicates a particle size decrease for both components 
(Hartstra, 1982; Dekkers and Linssen, 1989). Thus, fine and coarse particles both dissolve during this process, so that the paleomagnetic direction identified with $\mathrm{CD}$ is in principle the vector sum of the two components identified from direct TD (Figure 6d, g). Tauxe et al. (1980) conducted chemical leaching on Siwalik red beds in which the dominant magnetic carrier is hematite and found that the bulk remanent coercivity decreases after acid leaching, so they deduced that hematite pigment is magnetically harder than specularite because they assumed that only pigment was dissolved. Our results provide a reasonable explanation for the decreased bulk coercivity, where both low and high coercivity components dissolve during acid leaching (Figure 4d-f). Hematite is presumably present in various forms with diverse origins (Walker et al., 1981), which refines the commonly held view that hematite in red beds can be divided into just two groups: pigment and detrital specularite. Authigenic hematite occurs not only as pigment, but also as microcrystalline, polycrystalline, and monocrystalline grains with sizes in the micrometer range (Walker et al., 1981), which will not dissolve as readily as pigment. Therefore, $\mathrm{CD}$ is not so effective in removing secondary hematite with a wide particle size distribution. However, for red bed samples with distinct particle size distributions, such as pigment and specularite, CD could provide meaningful results (Henry, 1979; Tan et al., 2007).

\subsection{Remagnetization mechanism for the steep magnetization component}

A strong secondary vertically-directed magnetization component is often observed in Triassic samples from South China (Figure 8), including the studied Huangmaqing Formation in Nanjing (Kent et al., 1986, 1987; Opdyke et al., 1986; Su et al., 2005), the Anshun and Huaxi Formations in Guizhou province (Huang and Opdyke, 1996, 2015) and Hubei province (Huang and Opdyke, 1997, 2000), the Badong Formation in the border area between Sichuan, Hubei, and Hunan provinces (Huang and Opdyke, 1991, 1992), and the 
370 Tongtoujian Formation in Anhui province (Gilder et al., 1999; Su et al., 2005). However, the origin of this component is unclear (Opdyke et al., 1986). Previous studies have proposed that it might represent a multicomponent magnetization that yields a vertical resultant, with overprinting in a post-folding steeply inclined magnetic field (Opdyke et al., 1986) that might be related to late Mesozoic Yanshanian orogenic activity in these parts of South China (Kent et al., 1987; Wang and van der Voo, 1993), which led to substantial intracontinental tectonic rotations.

Red bed remagnetization usually results from secondary hematite formation via crystallization from solution or by mineral alteration. For the former mechanism, the CRM can record faithfully the magnetic field direction if it is a single-stage growth process (Stokking and Tauxe, 1987, 1990a; Jiang et al., 2015), while the magnetization direction for the latter mechanism will be controlled by both the remanence of the parent mineral(s) and the ambient magnetic field direction (Heider and Dunlop, 1987; Stokking and Tauxe, 1990b; Madsen et al., 2002). In our experiments, only hematite components with unblocking temperatures between $\sim 650^{\circ} \mathrm{C}$ and $685^{\circ} \mathrm{C}$ are interpreted as a $\mathrm{ChRM}$ in the direct TD results (Figure 2). However, based on CD-TD treatment of a three-component IRM, magnetite is detected in the low-coercivity component with a Curie temperature below $600{ }^{\circ} \mathrm{C}$ after $\mathrm{CD}$ (Figure 4a-c); this component is not observed in direct TD results for a three-component IRM because hematite is so dominant ( $\mathrm{Su}$ et al., 2005). A Verwey transition is also more evident in low-temperature ZFC curves for samples after CD treatment (Figure 5). We deduce that this magnetite is concealed by its small concentration with respect to the large hematite pigment concentration, which precludes its detection by direct TD. Magnetite may also be a parent mineral for secondary hematite.

Paleomagnetic poles of Comp B (Figure 9) cluster alongside hematite-based poles from previous studies with DRM unblocking between 670 and $690{ }^{\circ} \mathrm{C}$ and close to the 

indicates that Comp B is a primary NRM component. However, the paleomagnetic pole for Comp A lies far from the apparent polar wander path of the South China Block (Figure 9), which suggests that the recording of Comp A was controlled not only by the ambient paleomagnetic field, but also by additional factors. Parent magnetic particles can control second-generation particles through magnetostatic or exchange interactions (Stokking and Tauxe, 1990b), which leads to a CRM with a direction intermediate between the ambient magnetic field direction and the parent magnetic mineral direction (Heider and Dunlop, 1987; Stokking and Tauxe, 1990b). Late Mesozoic Yanshanian orogenic activity occurred could have caused conditions required for magnetite oxidation (Kent et al., 1987). In addition, the stress field of an orogeny can play a role in CRM acquisition by deviating it from the ambient field direction (Nagata, 1970; Gilder, 2007). Therefore, we suggest that the direction of the secondary component was controlled by several factors. Before the orogenic activity and diagenesis, the paleomagnetic field is inferred to have been recorded faithfully by Comp B, which is carried by detrital magnetite and hematite. However, during or after tectonic activity, magnetite oxidation would have been promoted by the accompanying temperature increase, and could have been accomplished by fluid flow or by pressure solution (Housen et al., 1993). During this process, a tectonically rotated parent remanence carried by magnetite with the influence of a contemporaneous ambient geomagnetic field and stress field generated by tectonic activity are argued to have produced the steep downward-directed magnetization in the studied samples. We suggest that this is why a steep magnetization component is commonly observed in different areas of the South China Block. 


\section{Conclusions}

Based on systematic thermal and chemical demagnetization, and rock magnetic analysis, thermal demagnetization is shown to be more effective in isolating an apparently primary magnetization than chemical demagnetization in red beds from South China. Two remanence components carried by secondary and primary hematite are isolated with thermal demagnetization, where the latter records a paleomagnetic direction that is consistent with published results. However, chemical demagnetization fails to extract a ChRM direction from the remagnetized component due to simultaneous dissolution of both fine and coarser hematite particles.

The presence of magnetite provides clues to the remagnetization mechanism in these samples. The CRM carried by secondary hematite is interpreted to have been generated by magnetite oxidation during tectonic activity. Therefore, the secondary magnetization with steep inclination, which is observed commonly in Triassic samples from different areas of the South China Block, is interpreted to have been influenced by a combination of the remanence carried by parent magnetite, the orogenic stress field, and the contemporaneous geomagnetic field direction during deformation. Our results shed new light on interpretation of paleomagnetic results from remagnetized red beds and are significant for tectonic studies of southern China.

Acknowledgements

442 discussions about this work. This study was supported by the National Key R\&D Program of China (2016YFA0601903), the National Natural Science Foundation of China (grants 
and Air-Sea Interaction (GASI-GEOGE-03), and Chinese Continental Shelf Deep Drilling Program (GZH201100202). Z.X.J. further acknowledges support from the China Postdoctoral Science Foundation (2015T80131). A.P.R. acknowledges support from the Australian Research Council (grant DP120103952).

\section{References}

Achache, J., Courtillot, V., Xiu, Z.Y., 1984. Paleogeographic and tectonic evolution of southern Tibet since middle Cretaceous time: new paleomagnetic data and synthesis. J. Geophys. Res. 89, 10311-10339.

Burek, P.J., 1969. Device for chemical demagnetization of red beds. J. Geophys. Res. 74, $6710-6712$.

Butler, R.F., 1992. Paleomagnetism: Magnetic Domains to Geologic Terranes, Blackwell.

Collinson, D., 1965.The remanent magnetization and magnetic properties of red sediments.Geophys. J. R. Astron. Soc. 10, 105-126.

Collinson, D., 1974. The role of pigment and specularite in the remanent magnetism of red sandstones. Geophys. J. R. Astron. Soc. 38, 253-264.

Collinson, D.W., 1975. Instruments and techniques in paleomagnetism and rock magnetism. Rev. Geophys. 13, 659-686.

Cornell, R., Giovanoli, R., 1993. Acid dissolution of hematites of different morphologies. Clay Miner. 28, 223-232.

Creer, K., 1961.Superparamagnetism in red sandstones. Geophys. J. R. Astron. Soc. 5, $16-28$.

Creer, K., 1968. Palaeozoic palaeomagnetism. Nature 219, 246-250.

Dekkers, M.J., 2012. End-member modelling as an aid to diagnose remagnetization: a brief review. Geol. Soc. Lond. Spec. Publ. 371, 253-269. 
Dekkers, M., Linssen, J., 1989. Rockmagnetic properties of fine-grained natural low-temperature haematite with reference to remanence acquisition mechanisms in red beds.Geophys.J. Int. 99, 1-18.

Deng, C., Liu, Q., Wang, W., Liu, C., 2007. Chemical overprint on the natural remanent magnetization of a subtropical red soil sequence in the Bose Basin, southern China. Geophys. Res. Lett. 34, L22308, doi:22310.21029/22007GL031400.

Dobson, J.P., Heller, F., 1992. Remagnetization in southeast China and the collision and suturing of the Huanan and Yangtze Blocks. Earth Planet. Sci. Lett. 111, 11-21.

Dunlop, D.J., Özdemir, Ö., 1997. Rock Magnetism: Fundamentals and Frontiers, Cambridge University Press.

Elmore, R.D., McCabe, C., 1991. The occurence and origin of remagnetization in the sedimentary rocks of North America. Rev. Geophys. 29, 377-383.

Elmore, R.D., Muxworthy, A.R., Aldana, M., 2012. Remagnetization and chemical alteration of sedimentary rocks. Geol. Soc. Lond. Spec. Publ.371, 1-21.

Enkin, R., Courtillot, V., Leloup, P., Yang, Z., Xing, L., Zhang, J.,Zhuang, Z., 1992. The paleomagnetic record of uppermost Permian, Lower Triassic rocks from the South China Block. Geophys. Res.Lett.19, 2147-2150.

Enkin, R.J., 2003. The direction-correction tilt test: an all-purpose tilt/fold test for paleomagnetic studies. Earth Planet. Sci.Lett.212, 151-166.

Fisher, R., 1953. Dispersion on a sphere. Proc. R. Soc. Lond. A 217, 295-305.

Ge, X.H., 1987. Nappe structures in the Ningzhen Mountains. J. Changchun College Geol. (in Chinese) 17, 143-154.

Gilder, S., 2007. Magnetization, piezoremanence and stress demagnetization, In: Gubbins, D., Herrero-Bervera, E., eds. Encyclopedia of Geomagnetism and Paleomagnetism.Springer, 2599-2603. 
Gilder, S.A., Leloup, P.H., Courtillot, V., Chen, Y., Coe, R.S., Zhao, X., Xiao, W., Halim, N., Cogné, J.P., Zhu, R., 1999. Tectonic evolution of the Tancheng-Lujiang (Tan-Lu) fault via middle Triassic to Early Cenozoic paleomagnetic data. J. Geophys. Res. 104, $15365-15390$.

Globokar, D.M., 2014. Testing thermal viscous remanent magnetization (TVRM) as a tool to date geomorphic events. MS thesis. University of Washington.

Hartstra, R.L., 1982. Some rock magnetic parameters for natural iron-titanium oxides. PhD thesis. University of Utrecht.

Hashimoto, T., Hurst, T., Suzuki, A., Mogi, T., Yamaya, Y., Tamura, M., 2008. The role of thermal viscous remanent magnetisation (TVRM) in magnetic changes associated with volcanic eruptions: insights from the 2000 eruption of Mt Usu, Japan. J. Volcanol.Geotherm.Res. 176, 610-616.

Heider, F., Dunlop, D.J., 1987. Two types of chemical remanent magnetization during the oxidation of magnetite. Phys. Earth Planet. Inter. 46, 24-45.

Henry, S.G., 1979. Chemical demagnetization: methods, procedures, and applications through vector analysis. Can. J. Earth Sci. 16, 1832-1841.

Heslop, D., Dekkers, M., Kruiver, P., Van Oorschot, I., 2002. Analysis of isothermal remanent magnetization acquisition curves using the expectation-maximization algorithm. Geophys. J. Int. 148, 58-64.

Housen, B.A., Pluijm, B.A., Van der Voo, R., 1993. Magnetite dissolution and neocrystallization during cleavage formation: paleomagnetic study of the Martinsburg Formation, Lehigh Gap, Pennsylvania. J. Geophys. Res. 98, 13799-13813.

Hu, P., Liu, Q., Torrent, J., Barrón, V., Jin, C., 2013. Characterizing and quantifying iron oxides in Chinese loess/paleosols: implications for pedogenesis. Earth Planet. Sci. Lett. 
521

522

523

524

Huang, K., Opdyke, N.D., 1991. Paleomagnetism of Jurassic rocks from southwestern Sichuan and the timing of the closure of the Qinling suture. Tectonophysics 200, 299-316.

Huang, K., Opdyke, N.D., 1992. Paleomagnetism of Cretaceous to lower Tertiary rocks from southwestern Sichuan: a revisit. Earth Planet. Sci. Lett. 112, 29-40.

Huang, K., Opdyke, N.D., 1996. Severe remagnetization revealed from Triassic platform carbonates near Guiyang, Southwest China. Earth Planet. Sci. Lett. 143, 49-61.

Huang, K., Opdyke, N.D., 1997. Middle Triassic paleomagnetic results from central Hubei province, China and their tectonic implications. Geophys. Res. Lett. 24, 1571-1574.

Huang, K., Opdyke, N.D., 2000. Magnetostratigraphic investigations of the Middle Triassic Badong Formation in South China. Geophys. J. Int. 142, 74-82.

Huang, K., Opdyke, N.D., 2015. Post-folding magnetization of the Triassic rocks from western Guizhou and southern Yunnan provinces: new evidence for large clockwise rotations in the Simao Terrane. Earth Planet. Sci. Lett. 423, 155-163.

Iosifidi, A.G., Mac Niocaill, C., Khramov, A.N., Dekkers, M.J., Popov, V.V., 2010. Palaeogeographic implications of differential inclination shallowing in Permo-Carboniferous sediments from the Donets basin, Ukraine. Tectonophysics 490, $229-240$.

Jiang, Z.X., Liu, Q., Barrón, V., Torrent, J., Yu, Y., 2012. Magnetic discrimination between Al-substituted hematites synthesized by hydrothermal and thermal dehydration methods and its geological significance. J. Geophys. Res. 117, B02102, doi:02110.01029/02011JB008605. 
Jiang, Z.X., Liu, Q., Dekkers, M.J., Colombo, C., Yu, Y., Barrón, V., Torrent, J., 2014. Ferro and antiferromagnetism of ultrafine-grained hematite. Geochem. Geophys. Geosyst. $15,2699-2712$.

Jiang, Z.X., Liu, Q., Dekkers, M.J., Tauxe, L., Qin, H., Barrón, V., Torrent, J., 2015. Acquisition of chemical remanent magnetization during experimental ferrihydrite-hematite conversion in Earth-like magnetic field - implications for paleomagnetic studies of red beds. Earth Planet. Sci. Lett. 428, 1-10.

Jin, C., Liu, Q., 2011. Remagnetization mechanism and a new age model for L9 in Chinese loess. Phys. Earth Planet. Inter. 187, 261-275.

Katz, B., Elmore, R.D., Cogoini, M., Engel, M.H., Ferry, S., 2000.Associations between burial diagenesis of smectite, chemical remagnetization, and magnetite authigenesis in the Vocontian trough, SE France. J.Geophys.Res. 105, 851-868.

Kent, D.V., Opdyke, N.D., 1978. Paleomagnetism of the Devonian Catskill red beds: evidence for motion of the coastal New England-Canadian maritime region relative to cratonic North America. J. Geophys. Res. 83, 4441-4450.

Kent, D.V., 1985. Thermoviscousremagnetization in some Appalachian limestones.Geophys. Res.Lett.12, 805-808.

Kent, D.V., Xu, G., Huang, K., Zhang, W., Opdyke, N.D., 1986. Paleomagnetism of upper Cretaceous rocks from South China. Earth Planet. Sci. Lett. 79, 179-184.

Kent, D.V., Zeng, X., Zhang, W.Y., Opdyke, N.D., 1987. Widespread late Mesozoic to Recent remagnetization of Paleozoic and lower Triassic sedimentary rocks from South China. Tectonophysics 139, 133-143.

Kirschvink, J.L., Kopp, R.E., Raub, T.D., Baumgartner, C.T., Holt, J.W., 2008. Rapid, precise, and high-sensitivity acquisition of paleomagnetic and rock-magnetic data: 
development of a low-noise automatic sample changing system for superconducting rock magnetometers. Geochem. Geophys. Geosyst. 9, Q05Y01, doi:10.1029/2007GC001856.

Kruiver, P.P., Dekkers, M.J., Heslop, D.,2001. Quantification of magnetic coercivity components by the analysis of acquisition curves of isothermal remanent magnetisation. Earth Planet. Sci.Lett. 189, 269-276.

Larson, E.E., 1981. Selective destructive demagnetization-another microanalytic technique in rock magnetism. Geology 9, 350-355.

Larson, E.E., Walker, T.R., 1975.Development of chemical remanent magnetization during early stages of red-bed formation in Late Cenozoic sediments, Baja California. Geol. Soc. Am.Bull.86, 639-650.

Liu, C., Ge, K., Zhang, C., Liu, Q., Deng, C., Zhu, R., 2011. Nature of remagnetization of Lower Triassic red beds in southwestern China. Geophys. J. Int. 187, 1237-1249.

Lowrie, W., 1990. Identification of ferromagnetic minerals in a rock by coercivity and unblocking temperature properties. Geophys. Res. Lett. 17, 159-162.

Lu, G., McCabe, C., Henry, D.J., Schedl, A., 1994. Origin of hematite carrying a Late Paleozoic remagnetization in a quartz sandstone bed from the Silurian Rose Hill Formation, Virginia, USA. Earth Planet. Sci. Lett. 126, 235-246.

Madsen, K.N., Walderhaug, H., Torsvik, T., 2002. Erroneous fold tests as an artifact of alteration chemical remanent magnetization. J. Geophys. Res. 107, doi:10.1029/2001JB000805.

McCabe, C., Elmore, R.D., 1989. The occurrence and origin of Late Paleozoic remagnetization in the sedimentary rocks of North America. Rev. Geophys. 27, $471-494$ 
591

592

593

McClelland-Brown, E., 1982. Discrimination of TRM and CRM by blocking-temperature spectrum analysis. Phys. Earth Planet. Inter. 30, 405-414.

McClelland, E., 1996. Theory of CRM acquired by grain growth, and its implications for TRM discrimination and palaeointensity determination in igneous rocks. Geophys. J. Int. $126,271-280$.

McFadden, P., McElhinny, M., 1990.Classification of the reversal test in palaeomagnetism.Geophys. J. Int.103, 725-729.

Nagata, T., 1970.Effects of a uniaxial compression on remanent magnetizations of igneous rocks.Pure Appl. Geophys.78, 100-109.

Opdyke, N.D., Huang, K., Xu, G., Zhang, W., Kent, D.V., 1986. Paleomagnetic results from the Triassic of the Yangtze Platform. J. Geophys. Res. 91, 9553-9568.

Park, J.K., 1970. Acid leaching of red beds and the relative stability of the red and black magnetic components. Can. J. Earth Sci. 7, 1086-1092.

Piper, J.D.A., Thomas, D.N., Share, S., Rui, Z.Q., 1999. The palaeomagnetism of (Mesoproterozoic) Eriksfjord Group red beds, South Greenland: multiphase remagnetization during the Gardar and Grenville episodes. Geophys. J. Int. 136, $739-756$.

Roberts, A.P., 2015. Magnetic mineral diagenesis. Earth-Sci. Rev. 151, 1-47.

Roberts, A.P., Weaver, R., 2005. Multiple mechanisms of remagnetization involving sedimentary greigite $\left(\mathrm{Fe}_{3} \mathrm{~S}_{4}\right)$. Earth Planet. Sci. Lett. 231, 263-277.

Rowan, C.J., Roberts, A.P., 2006. Magnetite dissolution, diachronous greigite formation, and secondary magnetizations from pyrite oxidation: unravelling complex 
magnetizations in Neogene marine sediments from New Zealand. Earth Planet. Sci. Lett. 241, 119-137.

Scotese, C.R., Van derVoo, R., McCabe, C., 1982.Paleomagnetism of the Upper Silurian and Lower Devonian carbonates of New York State: evidence for secondary magnetizations residing in magnetite. Phys. Earth Planet.Inter.30, 385-395.

Steiner, M.B., Lucas, S.G., 2000. Paleomagnetism of the Late Triassic Petrified Forest Formation, Chinle Group, western United States: further evidence of "large" rotation of the Colorado Plateau. J. Geophys. Res. 105, 25,791-25,808.

Stokking, L.B., Tauxe, L., 1987. Acquisition of chemical remanent magnetization by synthetic iron oxide. Nature 327, 610-612.

Stokking, L., Tauxe, L., 1990a. Properties of chemical remanence in synthetic hematite: testing theoretical predictions.J. Geophys. Res.95, 12,639-12,652.

Stokking, L.B., Tauxe, L., 1990b. Multicomponent magnetization in synthetic hematite. Phys. Earth Planet. Inter. 65, 109-124.

Su, L., Yang, Z., Sun, Z., Yang, T., Zaman, H., Takemoto, K., Otofuji, Y., 2005. Regional deformational features of the South China Block inferred from Middle Triassic palaeomagnetic data. Geophys. J. Int. 162, 339-356.

Sugimoto, T., Muramatsu, A., Sakata, K., Shindo, D., 1993.Characterization of hematite particles of different shapes.J. Colloid Interface Sci. 158, 420-428.

Sugimoto, T., Itoh, H., Mochida, T., 1998. Shape control of monodisperse hematite particles by organic additives in the gel-sol system. J. Colloid Interface Sci. 205, 42-52.

Sun, Z., Yang, Z., Pei, J., Yang, T., Wang, X., 2006. New Early Cretaceous paleomagnetic data from volcanic and red beds of the eastern Qaidam Block and its implications for 
Tan, X., Kodama, K.P., Gilder, S., Courtillot, V., 2007. Rock magnetic evidence for inclination shallowing in the Passaic Formation red beds from the Newark basin and a systematic bias of the Late Triassic apparent polar wander path for North America. Earth Planet. Sci. Lett. 254, 345-357.

Tauxe, L., Kent, D.V., Opdyke, N.D., 1980. Magnetic components contributing to the NRM of Middle Siwalik red beds. Earth Planet. Sci. Lett. 47, 279-284.

Van der Voo, R., Torsvik, T.H., 2012. The history of remagnetization of sedimentary rocks: deceptions, developments and discoveries. Geol. Soc. Lond. Spec. Publ. 371, 23-53.

Walker, T.R., Larson, E.E., Hoblitt, R.P., 1981. Nature and origin of hematite in the Moenkopi Formation (Triassic), Colorado Plateau: a contribution to the origin of magnetism in red beds. J. Geophys. Res. 86, 317-333.

Wang, Z., Van der Voo, R., 1993. Pervasive remagnetization of Paleozoic rocks acquired at the time of Mesozoic folding in the South China Block. J. Geophys. Res. 98, $1729-1741$.

Watson, G.S., Enkin, R.J., 1993. The fold test in paleomagnetism as a parameter estimation problem. Geophys. Res. Lett. 20, 2135-2137.

Weaver, R., Roberts, A.P., Barker, A.J., 2002. A late diagenetic (synfolding) magnetization carried by pyrrhotite: implications for paleomagnetic studies from magnetic iron sulphide-bearing sediments. Earth Planet. Sci. Lett. 200, 371-386.

Xue, H., Shi, H.S., Xu, G.Q., 1985. Nappe structure and folds on Nanjing-Zhenjiang mountain range. Bull. Nanjing Inst. Geol. M.R., Chinese Acad. Geol. Sci. 6, 1-14. 
Yang, Z., Besse, J., 2001. New Mesozoic apparent polar wander path for south China: tectonic consequences. J.Geophys.Res. 106, 8493-520.

Zaman, H., Torii, M., 1999. Palaeomagnetic study of Cretaceous red beds from the eastern Hindukush ranges, northern Pakistan: palaeoreconstruction of the Kohistan-Karakoram composite unit before the India-Asia collision. Geophys. J. Int. 136, 719-738.

Zijderveld, J.D.A., 1967. A.C. demagnetization of rocks: analysis of results. In: Methods in Palaeomagnetism, Collinson, D.W., Creer, K.M., Runcorn, S.K., eds. Elsevier, 254-286.

\section{Figure Captions}

Figure 1. (a) Geological map of the study area in Nanjing, where the inset is a tectonic sketch map of South China (NCB and SCB represent North China Block and South China Block, respectively). The star denotes the locality sampled in this study. Abbreviations: $\mathrm{Q}=$ Quaternary; $\mathrm{K}=$ Cretaceous; $\mathrm{J}=$ Jurassic; $\mathrm{T}=$ Tertiary; $\mathrm{T}_{2} \mathrm{~h}=$ Huangmaqing formation; $\mathrm{T}_{2} \mathrm{X}$ $=$ Xujiashan formation; $\delta \mu_{5}=$ diorite porphyrite; $\eta о \pi=$ Quartz monzonitic porphyry. (b) Representative photograph of the sampled section with strike/dip orientation of strata of $200^{\circ} / 21^{\circ}$. (c) Oriented samples prior to chemical demagnetization with $0.5-\mathrm{mm}$ drill holes in their surfaces. (d) Oriented samples after chemical demagnetization.

Figure 2. Magnetic characteristics of three typical groups of red bed samples. (a-1)/(b-1)/(c-1) Orthogonal vector demagnetization plots (Zijderveld, 1967) with stepwise thermal demagnetization data for representative samples, where solid and open circles represent horizontal and vertical projections, respectively. The inset in each subfigure is a 
zoom of the orthogonal plot from $\sim 650$ to $690{ }^{\circ} \mathrm{C}$. (a-2)/(b-2)/(c-2) Hysteresis loops after paramagnetic slope correction for representative samples. (a-3)/(b-3)/(c-3) IRM component analysis, where orange, blue, and purple lines indicate the low $\left(\operatorname{IRM}_{\mathrm{L}}\right)$ and high coercivity $\left(\mathrm{IRM}_{\mathrm{H}}\right)$ components, and the sum of these components (sum), respectively. Open circles indicate raw IRM gradient data (raw data). (a-4)/(b-4)/(c-4) Temperature dependence of magnetization for representative samples, where the purple and blue lines indicate heating and cooling cycles, respectively.

Figure 3. Normalized stepwise thermal decay curves for representative samples, where the shaded area represents the range of values from the model of Jiang et al. (2015) to discriminate between a chemical remanent magnetization (CRM) and a detrital remanent magnetization (DRM).

Figure 4. The response of three IRM coercivity fractions to chemical-thermal demagnetization. (a-c) Progressive chemical-thermal demagnetization of a three-component IRM produced by magnetizing samples in $0.05,0.5$, and $2.5 \mathrm{~T}$ fields that were applied along the $\mathrm{X}$ (open circles), Y (solid circles), and Z sample axes (solid cross), respectively. (d-f) Coercivity variations during chemical demagnetization, where $B_{\mathrm{cr}}$ is for the bulk sample, and $B_{\mathrm{L} 1 / 2}$ and $B_{\mathrm{H} 1 / 2}$ are identified from IRM component fitting (Kruiver et al., 2001).

Figure 5. Representative zero-field cooled (ZFC) warming curves for the three identified groups of samples before and after CD treatment. (a-c) ZFC curves for typical samples (NJ16-8, NJ7-8, and NJ12-9) before CD treatment; (d-f) ZFC curves for typical samples (NJ16-8, NJ7-8, and NJ12-9) after CD treatment. Dashed lines are derivatives of the ZFC warming curves. 
Figure 6. Comparison of direct thermal demagnetization results (black symbols) and

710

711

712

713

714

715

716

717

718

719

720

721

722

723

724

725

726

727

chemical demagnetization (light grey) followed by thermal demagnetization (dark grey) results for representative samples. (a, d, g) Orthogonal vector demagnetization plots; $(b, e, h)$ equal area stereographic projections of stepwise demagnetization data; and (c, f, i) NRM decay curves (normalized vector differences) for chemical demagnetization and subsequent thermal demagnetization treatments.

Figure 7. Stereographic projections for the directions of (a) component A (Comp A) and (b) component B (Comp B) acquired after direct thermal demagnetization, and (c, d) Comp A and B after combined chemical and thermal demagnetization (CD-TD). The sky-blue solid circles represent mean paleomagnetic directions for each site, while the ellipses indicate 95\% confidence intervals about each mean. The red symbols in (b) represent reference data from Su et al. (2005) for the study area.

Figure 8. Stereographic projections for the directions of the remagnetized component from different areas of South China. The sky-blue solid circles represent mean directions for each site, while the ellipses indicate $95 \%$ confidence intervals about each mean.

Figure 9. Equal area projection of Middle Triassic paleomagnetic poles (yellow solid circles) with associated 95\% confidence ellipses for the South China Block (SCB) (I: Tongling, Su et al. (2005); II: Nanjing, this study; III: Nanjing, Su et al. (2005); IV: Nanzhang, Su et al. (2005); V: Jingmen-Dangyang, Huang and Opdyke (1997); VI: Nanjing, Opdyke et al. (1986)). Black solid circles represent the apparent polar wander path for the SCB from Yang and Besse (2001) and Enkin et al. (1992): P2 = Late Permian; T1 = Early Triassic; T3 = Late 
733 Triassic; J1 = Early Jurassic; J3 = Late Jurassic; K1 = Early Cretaceous; K2 = Late

734 Cretaceous; $\mathrm{E}=$ Eogene; $\mathrm{N}=$ Neogene. Purple solid circles represent the paleomagnetic pole 735 for Comp A from this and previous studies.

736

737 Table Captions

738

739 Table 1. Site and formation statistics for the Huangmaqing Formation from Nanjing ${ }^{\mathrm{a}}$.

$740{ }^{\mathrm{a}}$ Bedding is strike/dip (in degrees), while $\mathrm{B}$ and $\mathrm{A}$ represent components $\mathrm{B}$ and A, 741 respectively. $n / N$ is the number of samples used/number of samples measured. $D, I$ are the 742 declination and inclination, respectively. $\alpha_{95}$ is the radius of the $95 \%$ confidence circle about the mean direction. $k_{s}$ is the Fisher (1953) precision parameter after bedding tilt correction.

Table 2. Coercivity variation summary for IRM components from Group I, II, and III samples after each chemical leaching step ${ }^{\mathrm{a}}$. ${ }^{\mathrm{a}} B_{\mathrm{cr}}$ is the bulk remanent coercivity (in $\mathrm{mT}$ ) determined from back field demagnetization curves. $B_{\mathrm{H} 1 / 2}$ and $B_{\mathrm{L} 1 / 2}$ represent the coercivity of the magnetic 'hard' and 'soft' components, respectively (both in $\mathrm{mT}$ ), identified from IRM analysis. 


\section{Remagnetization mechanisms in Triassic red beds from South China}

2 9 Science and Technology, Qingdao 266061, P.R. China Chinese Academy of Sciences, Beijing 100029, P.R. China 2601, Australia Budapestlaan 17, 3584 CD Utrecht, The Netherlands 100048, P.R. China

*Corresponding author: Qingsong Liu (liux0272@yahoo.com)

\author{
Zhaoxia Jiang, ${ }^{\mathrm{a}, \mathrm{b}, \mathrm{c}}$, Qingsong Liu ${ }^{\mathrm{b}, \mathrm{d}}$, Mark J. Dekkers ${ }^{\mathrm{e}}$, Xiang Zhao ${ }^{\mathrm{c}}$, \\ Andrew P. Roberts ${ }^{\mathrm{c}}$, Zhenyu Yang ${ }^{\mathrm{f}}$, Chunsheng Jin ${ }^{\mathrm{a}}$, and Jianxing Liu ${ }^{\mathrm{g}, \mathrm{b}}$
}

${ }^{\mathrm{a}}$ State Key Laboratory of Lithospheric Evolution, Institute of Geology and Geophysics,

${ }^{\mathrm{b}}$ Laboratory for Marine Geology, Qingdao National Oceanography Laboratory for Marine

${ }^{c}$ Research School of Earth Sciences, Australian National University, Canberra, ACT

${ }^{\mathrm{d}}$ South University of Science \& Technology of China, Shenzhen, 518055, P.R. China

${ }^{\mathrm{e}}$ Department of Earth Sciences, Faculty of Geosciences, Utrecht University,

${ }^{\mathrm{f} C o l l e g e}$ of Resource Environment and Tourism, Capital Normal University, Beijing,

${ }^{\mathrm{g}}$ Key Laboratory of Marine Sedimentology and Environmental Geology, First Institute of Oceanography, State Oceanic Administration, Qingdao, 266061, P.R. China 


\section{Abstract}

Paleogeographic reconstructions based on paleomagnetic data rely on the reliability of the natural remanent magnetization (NRM) being primary. Remagnetizations can be common in many rock types, including late Paleozoic and Mesozoic red beds, and they complicate paleogeographic interpretations. Extracting the primary NRM from partially remagnetized rocks, and understanding the remagnetization mechanism are important in these contexts. We carried out a systematic paleomagnetic study of red bed samples from the Triassic Huangmaqing Formation, Nanjing $\left(32.0^{\circ} \mathrm{N}, 118.9^{\circ} \mathrm{E}\right)$, South China. Two NRM components carried by secondary and primary hematite are isolated in 47 of the 94 samples studied, where the latter component has a direction in stratigraphic coordinates of $D=29.2^{\circ}, I=34.6^{\circ}\left(\alpha_{95}=10.9^{\circ}, 47\right.$ samples from 6 sites $)$ that yield a paleopole of $\lambda$ $=60.8^{\circ} \mathrm{N}, \phi=228.1^{\circ} \mathrm{E}, d p / d m=12.5 / 7.2$, which is consistent with Triassic pole positions for the South China Block. A secondary chemical remanent magnetization (CRM) $(D=$ $\left.227.1^{\circ}, I=80.8^{\circ}, \alpha_{95}=7.3^{\circ}\right)$ is documented in all 94 samples from 10 sites and is carried by pigmentary hematite that is inferred to have been generated by magnetite oxidation during orogenic activity. This secondary component has steep inclinations and is interpreted to be influenced by a combination of the remanence carried by original parent magnetite, the orogenic stress field, and the prevailing geomagnetic field direction during deformation. This CRM direction is recorded commonly by red beds from the South China Block, and is significant for regional tectonic studies in the area.

Keywords: remagnetization, red beds, hematite, chemical remanent magnetization, detrital remanent magnetization, South China Block, Triassic 


\section{Introduction}

Remagnetization, a phenomenon by which the natural remanent magnetization (NRM) is acquired in an ambient magnetic field of a much younger age than that of the rock or sediment itself, complicates interpretation of paleomagnetic data from rocks, soils, and sediments (McCabe and Elmore, 1989; Suk et al., 1993; Lu et al., 1994; Piper et al., 1999; Roberts and Weaver, 2005; Rowan and Roberts, 2006;Deng et al., 2007; Jin and Liu, 2011; Liu et al., 2011; van der Voo and Torsvik, 2012; Roberts, 2015). Generally, the mechanisms by which remagnetizations occur involve mineral transformations during diagenesis, i.e. magnetite, greigite, or pyrrhotite formation (Katz et al., 2000; Weaver et al., 2002; Roberts and Weaver, 2005), chemical weathering in moist, tropical weathering and soil-forming environments (Creer, 1961, 1968; Jin and Liu, 2011; Liu et al., 2011), or the acquisition of thermoviscous remanent magnetization (Scotese et al., 1982; Kent, 1985; Hashimoto et al., 2008; Globokar, 2014). Acquisition of secondary magnetizations through any such mechanism will obscure the primary paleomagnetic record (McCabe and Elmore, 1989; van der Voo and Torsvik, 2012), and may lead to inaccurate paleomagnetic interpretations if not recognized (McCabe and Elmore, 1989; van der Voo and Torsvik, 2012; Dekkers, 2012).

In the South China Block (SCB), widely distributed late Paleozoic and Mesozoic red beds have been subjected to extensive paleomagnetic investigations, aimed at reconstructing its paleogeography (e.g. Achache et al., 1984; Zaman and Torii, 1999; Steiner and Lucas, 2000; Sun et al., 2006). However, the reliability of the NRM recorded by red sediments is often questioned because widespread and often pervasive remagnetizations have been documented (Dobson and Heller, 1992; Wang and van der Voo, 1993; Huang and Opdyke, 1996; Liu et al., 2011). The prevalent remagnetization scenario is considered to be some form of chemical remanent magnetization (CRM) 
acquired long after deposition (McCabe and Elmore, 1989; Elmore et al., 2012; van der Voo and Torsvik, 2012). The most frequently occurring CRM carrier in red beds is hematite pigment, which can overprint a detrital remanent magnetization (DRM) carried by primary hematite. Therefore, discrimination of a CRM from a DRM is central to paleomagnetic studies of red beds. Hematites from different environments have distinct morphologies, crystallinity ranges, and magnetic properties (Collinson, 1965; Walker et al., 1981; Sugimoto et al., 1993, 1998; Jiang et al., 2012, 2014), which can be used to distinguish the origin of the hematite under investigation.

Thermal demagnetization (TD) is the most popular method for identifying a DRM or CRM in red beds due to their different unblocking temperature spectra (McClelland-Brown, 1982; Iosifidietal., 2010; Jiang et al., 2015). Detrital hematite has a narrow unblocking temperature spectrum at the highest temperatures $\left(\sim 660-680{ }^{\circ} \mathrm{C}\right)$ because it usually occurs as stable single domain (SD) particles with often close to ideal stoichiometry. Pigmentary hematite is typically finer-grained with sizes closer to the superparamagnetic (SP) to SD threshold size, so that it has a much broader unblocking temperature spectrum at lower temperatures $\left(300-650{ }^{\circ} \mathrm{C}\right)$ (Stokking and Tauxe, 1990a; Jiang et al., 2015). Alternating field demagnetization (AFD) is also important in paleomagnetic studies, but it is not particularly effective for treating red beds because hematite has high coercivities (Butler, 1992; Dunlop and Özdemir, 1997). Chemical demagnetization (CD) has been used only occasionally for analysing red sediments with multiple NRM components within a single sample (Burek, 1969; Collinson, 1975; Kent and Opdyke, 1978; Henry, 1979; Tauxe et al., 1980; Tan et al., 2007). Most rocks contain a relatively large number of remanence-carrying grains that have variable chemical and physical properties. Ideally, the remanence in certain grains will be effectively removed by chemical dissolution during $\mathrm{CD}$, whereas in others it will remain 
unchanged. As the level of demagnetization (i.e. hematite dissolution) increases, the number of grains affected also increases (Larson, 1981). Grains that are more likely to acquire secondary magnetic components are more susceptible to lower levels of demagnetization. The fine-grained hematite pigment will dissolve first, leaving behind partially dissolved coarser specularite grains (Henry, 1979; Tauxe et al., 1980; Tan et al., 2007). This would allow identification of the NRM component carried by detrital specularite.

For remagnetized red beds, it is difficult to isolate the characteristic remanent magnetization (ChRM) and establish it as the primary NRM component, especially in pervasively remagnetized red beds. The relative effectiveness of the various demagnetization techniques to identify the advantages and disadvantages of each method has yet to be tested widely for remagnetized red beds. Therefore, in this study, we carried out systematic TD, CD, and combined CD-TD, with associated rock magnetic analysis, on 94 remagnetized red bed samples to assess their efficacy for paleomagnetic analysis of remagnetized red bed samples and to investigate the mechanisms by which remagnetization occurred.

\section{Sampling and measurements}

\subsection{Sampling}

The Middle Triassic Huangmaqing Formation is investigated here. A total of 94 standard paleomagnetic cores (10 sites) with $25-\mathrm{mm}$ diameter, were collected in a transect from the village of Xiawuqi to Zijinshan Hill to the northeast of Nanjing, South China $\left(32.0^{\circ} \mathrm{N}, 118.9^{\circ} \mathrm{E}\right)($ Figure 1a). The Huangmaqing Formation consists of clastic rocks, including purplish-red siltstones and fine sandstones (Figure 1b). The beds dip shallowly to the south $\left(7-22^{\circ}\right)$. Paleomagnetic samples were cored with a portable drill 
and were oriented magnetically. Core samples were cut into three cylindrical sister-specimens $1-\mathrm{cm}$ in length in the laboratory for TD, combined CD-TD treatment on NRM, and combined CD-TD treatment on three-orthogonal isothermal remanent magnetization (IRM) components (Lowrie, 1990). Fresh off-cuts that remained after cutting specimens were used for other rock magnetic measurements.

\subsection{Paleomagnetic measurements}

One set of sister-specimens (94 samples) was subjected to stepwise TD measurements in 33 steps up to $695{ }^{\circ} \mathrm{C}$ at $50{ }^{\circ} \mathrm{C}$ intervals from 20 to $600{ }^{\circ} \mathrm{C}$ and at $5{ }^{\circ} \mathrm{C}$ intervals from 600 to $695{ }^{\circ} \mathrm{C}$ using a thermal demagnetizer (PGL-100) developed at the Paleomagnetism and Geochronology Laboratory (PGL), Institute of Geology and Geophysics, Chinese Academy of Sciences, Beijing, China in a magnetically shielded room. Remanent magnetizations after each TD step were measured with a 2-G Enterprises RAPID three-axis magnetometer (Kirschvink et al., 2008).

A second set of sister-specimens was subjected to combined CD-TD treatment. First, specimens were subjected to chemical leaching experiments. To increase the surface area of samples for more pervasive acid percolation, $0.5-\mathrm{mm}$ diameter holes were drilled into each side of the cylinders (Figure 1c). CD was carried out using $8 \mathrm{~N}$ (normality) hydrochloric acid $(\mathrm{HCl})$. Specimens from each site were soaked in a plastic bottle with $100 \mathrm{ml}$ of acid. The specimen bottles were placed in a magnetically shielded space, where the ambient field was kept constant $(<200 \mathrm{nT})$ within a set of Helmholtz coils. Initially, specimens were measured magnetically after every three hours of leaching. Specimens were washed with distilled water at each step, and were dried in a furnace at $40^{\circ} \mathrm{C}$ in a magnetically shielded space before measuring the remaining NRM to prevent the wet specimens and still slightly acidic leachate from damaging the magnetometer. 
145 After each measurement the specimens were re-soaked in fresh acid (100 $\mathrm{ml}$ each time). After the first three steps, samples were soaked in acid for 24 hours at each step. When the remanence became stable at $\sim 20 \%$ of the initial NRM on further demagnetization, the leaching process was considered complete. Fourteen chemical leaching steps were performed, with three steps of 3-hour soakings and eleven steps of 24 hour soakings. Afterwards, the samples were subjected to a cycle of TD measurements to remove the remaining NRM.

\subsection{Rock magnetic measurements}

To investigate the magnetic mineralogy, hysteresis loops for 40 representative samples from all sites (4 samples from each site) were measured to a maximum field of 1 $\mathrm{T}$ using a Princeton Measurements Corporation vibrating sample magnetometer (MicroMagVSM 3900), from which the coervicity $\left(B_{\mathrm{c}}\right)$, saturation remanent magnetization $\left(M_{\mathrm{r}}\right)$, and saturation magnetization $\left(M_{\mathrm{s}}\right)$ were determined. Isothermal remanent magnetization (IRM) acquisition curves and back-field demagnetization curves were measured for the same samples to determine the coercivity of remanence $\left(B_{\text {cr }}\right)$. First derivatives of IRM acquisition curves were fitted with coercivity components following Kruiver et al. (2001) and Heslop et al. (2002). For further magnetic mineralogy analyses, the temperature dependence of magnetization (M-T) was measured in a steady $1 \mathrm{~T}$ field from room temperature to $800^{\circ} \mathrm{C}$ in air with a Magnetic Measurements variable field translation balance (VFTB). Zero-field cooled (ZFC) warming curves were measured with a Quantum Design Magnetic Properties Measurement System (MPMS XP-5, sensitivity $5.0 \times 10^{-10} \mathrm{Am}^{2}$ ) for samples before and after total $\mathrm{CD}$ treatment to detect changes in magnetic mineralogy. Samples were first cooled from room temperature to 15 $\mathrm{K}$ in zero field and were then exposed to a field of $5 \mathrm{~T}$ (this IRM is denoted as $\mathrm{IRM}_{5 \mathrm{~T}}$ ). 
After the magnetic field was switched off, $\mathrm{IRM}_{5 \mathrm{~T}}$ was measured from 15 to $300 \mathrm{~K}$ at 2.5 $\mathrm{K}$ intervals.

A final set of sister specimens was used for stepwise CD-TD measurements of a three-component IRM following the procedure of Lowrie (1990) to monitor the leaching and thermal behaviour of the different coercivity components. First, samples were magnetized in successively smaller fields along three mutually perpendicular sample axes (2.5 $\mathrm{T}$ along the $\mathrm{z}$-axis, $0.5 \mathrm{~T}$ along the $\mathrm{y}$-axis, and $0.05 \mathrm{~T}$ along the $\mathrm{x}$-axis, respectively). The samples were then subjected to CD-TD measurements following the same procedure as for the second group of sister-specimens in the NRM demagnetization process.

To measure magnetic property variations during $\mathrm{CD}$, fresh offcut samples were also subjected to 14 steps of stepwise chemical leaching in the same batch as the oriented samples for NRM demagnetization. Hysteresis loops and IRM acquisition curves were measured after each leaching step. This is the first study in which rock magnetic properties of red beds have been monitored during chemical leaching.

\section{Results}

\subsection{Paleo- and rock magnetic characterization of red bed samples}

Typical NRM intensities for the studied specimens are about $10^{-2} \mathrm{~A} / \mathrm{m}$. Based on TD results, samples can be divided into three groups. Samples from individual sites have similar demagnetization behaviour, i.e. most samples are allocated to the same group. Group I samples ( $\sim 39$ specimens / 4 sites $)$ have relatively straightforward demagnetization behaviour characterized by a single linear trajectory between 100 and $660{ }^{\circ} \mathrm{C}$ (Figure 2a-1). This indicates that hematite is a significant ChRM carrier. The magnetization direction is oriented to the northwest with moderate to steep-downward-directed inclinations in in-situ coordinates. Directions for each site 
before and after tilt correction are summarized in Table 1. They differ from the present-day geomagnetic field direction before bedding correction. M-T curves decrease gradually during heating and reach zero at $\sim 670^{\circ} \mathrm{C}$, which further indicates that hematite is the dominant magnetic mineral (Figure 2a-4). A maximum applied field of $1 \mathrm{~T}$ was insufficient to magnetically saturate the samples at room temperature, with a bulk coercivity $B_{\mathrm{c}}$ of $342 \mathrm{mT}$ determined from the hysteresis loop after slope correction between 0.9 and $1 \mathrm{~T}$ (Figure 2a-2). However, IRM component analysis indicates that two coercivity components can be identified, a dominant component with median acquisition field $\left(B_{\mathrm{H} 1 / 2}\right)$ of $600 \sim 630 \mathrm{mT}$ that contributes $90 \%$ of the IRM and a small component $(10 \%)$ with median acquisition field $\left(B_{\mathrm{L} 1 / 2}\right)$ of $\sim 100 \mathrm{mT}$ (Figure $\left.2 \mathrm{a}-3\right)$.

For Group II samples ( 14 specimens / 2 sites), two NRM components are identified from TD analysis (Figure 2b-1). Component A (Comp A) is isolated below $670{ }^{\circ} \mathrm{C}$, and accounts for $70-80 \%$ of the initial NRM intensity. It is northwest-directed with a steep positive inclination, close to the direction of Group I samples, which is distinct from the present-day geomagnetic field direction. A second component, designated as component B (Comp B), is resolved between 670 and $690{ }^{\circ} \mathrm{C}$ with 5 demagnetization steps and is directed to the northwest with a shallow negative inclination in geographic coordinates. M-T curves decay gradually to $670{ }^{\circ} \mathrm{C}$ and then drop to zero abruptly at $\sim 685^{\circ} \mathrm{C}$, which is consistent with the NRM TD results (Figure $2 \mathrm{~b}-4$ ). Bulk $B_{\mathrm{c}}$ for a representative sample is $\sim 398 \mathrm{mT}$ from an unsaturated hysteresis loop (Figure 2b-2), with two coercivity components identified from IRM analysis with $B_{\mathrm{H} 1 / 2}$ of $700 \sim 710 \mathrm{mT}$ (i.e. higher than that of Group I) and $B_{\mathrm{L} 1 / 2}$ of $\sim 200 \mathrm{mT}$ (Figure 2b-3) (higher than that of Group I).

Group III samples ( $\sim 33$ specimens / 4 sites) also have two magnetic components, where Comp A dominates up to $670{ }^{\circ} \mathrm{C}$ with a northeast direction and steep downward-directed inclination in situ, and Comp B is resolved from 670 to $690{ }^{\circ} \mathrm{C}$ with a 
northeast direction and shallow positive inclination (Figure 2c-1). M-T curves of Group III samples are similar to those of Group II samples, with magnetic ordering temperatures of $\sim 685{ }^{\circ} \mathrm{C}$ (Figure $2 \mathrm{c}-4$ ). The bulk $B_{\mathrm{c}}$ for representative Group III samples is $\sim 230 \mathrm{mT}$ (Figure 2c-2), and IRM acquisition curves can be fitted with two components with $B_{\mathrm{H} 1 / 2}$ of $\sim 430 \mathrm{mT}$ and $B_{\mathrm{L} 1 / 2}$ of $\sim 60-65 \mathrm{mT}$ (Figure $2 \mathrm{c}-3$ ), both lower than the equivalent fractions in Groups I and II.

The model of Jiang et al. (2015) was used to analyze NRM TD curves for the three sample groups to assess whether the NRM is a CRM or a DRM. Curves for Group I samples have a concave shape and decay to zero gradually, which is consistent with the expectation for CRM behaviour (Figure 3a). Samples from the other two groups yield curves with similar shapes to those expected for a DRM, with abrupt decreases to zero at $\sim 670-690{ }^{\circ} \mathrm{C}$ (Figure 3b). Based on TD and rock magnetic results, Group I samples are interpreted to have been completely remagnetized by a CRM, while samples from the other two groups are partially remagnetized and record a mixture of a CRM and a DRM.

\subsection{Rock magnetic monitoring of CD-TD behaviour of red bed samples}

To monitor the CD-TD behaviour of different coercivity components, stepwise CD-TD treatment of a three-component IRM was carried out on a series of sister specimens. Before CD treatment, the medium $(50-500 \mathrm{mT})$ and hard (>500 mT) components are dominant (Figure 4a-c). During stepwise CD treatment, the IRM decreases sharply to become constant after six steps for Group I samples (Figure 4a), while for the other two sample groups, the IRM is more resistant to CD treatment and ceases to decrease further after 12 and 8 steps, respectively (Figure 4b, c). During subsequent TD treatment, the medium coercivity component is dominant. The soft component for all samples is unblocked below $\sim 600{ }^{\circ} \mathrm{C}$, while the medium and hard 
components are completely unblocked at $\sim 680^{\circ} \mathrm{C}$. In addition, a weak Verwey transition

is detected in low-temperature ZFC curves (Figure 5a-c), which indicates that magnetite occurs in the samples. For samples after 14-step CD treatment, an obvious Verwey transition is observed but the IRM intensity has decreased to $10 \%$ of that before CD treatment (Figure 5d-f). We infer that the expression due to magnetite may be concealed by massive amounts of hematite in the non-leached samples. After CD treatment, hematite pigment is dissolved, so magnetite can be detected more easily with magnetic methods, which supports the notion that pigmentary hematite is dissolved preferentially, responsible for the latter two components.

IRM acquisition curves after each CD leaching step were determined for 52 samples.

Two coercivity components can be identified from the IRM acquisition curves, a 
(Figure 4a-c) and low temperature results (Figure 5), the low coercivity component with $B_{\mathrm{L} 1 / 2}$ around $20 \mathrm{mT}$ is interpreted to be magnetite.

\subsection{Comparison of chemical and thermal demagnetization results}

For Group I samples, the primary NRM is difficult to identify with TD because it is overprinted completely by a secondary CRM. However, a potentially meaningful ChRM component can be identified from TD results for Groups II and III. Group I samples have a brighter red colour and seem to be more weathered and pigmented than the others which could explain the absence of a primary ChRM. This raises the question of whether $\mathrm{CD}$ is more effective in isolating a ChRM in red beds, and whether it can resolve a ChRM for Group I.

TD only (referred to as 'direct TD'), CD, and combined CD-TD results are summarized in Figure 6. Group I samples have a single linear trajectory in both CD and TD; TD applied after completion of CD also reveals the same trajectory (Figure 6a). In equal-area projections, demagnetization trajectories for TD and CD-TD overlap (Figure 6b). For stepwise CD and TD, about half of the NRM was demagnetized by CD (Figure 6c), with CD causing bleaching of the initially red samples (Figure 1c, d). For Group II samples, direct TD and combined CD-TD yield contrasting results. A primary reversed polarity direction was extracted from direct TD, while for the stepwise CD-TD protocol, two components are identified. One component is similar to Comp A identified in the direct TD protocol, while the direction for the latter is almost a vector combination of the two components extracted from direct TD measurements (Figure 6d, e). Only 10\% of the NRM is left after CD (Figure 6f). For Group III samples, CD-TD reveals two components, which are essentially parallel to the two components identified from direct TD treatment (Figure $6 \mathrm{~g}$ ), with almost $85 \%$ of the NRM removed by CD. 


\section{Discussion}

297

298

299

300

301

302

303

304

305

306

307

308

309

310

311

312

313

314

\subsection{Comparison of the effectiveness of thermal and chemical demagnetization}

TD results allow identification of two components (Comps A and B) in samples from Groups II and III (6 sites), while only Comp A can be distinguished in samples from Group I (4 sites). Site mean directions (Fisher, 1953) are presented in Figure 7 and Table 1. The formation site-averaged direction for Comp A for all three groups is $D=355.1^{\circ}, I$ $=80.5^{\circ}\left(\mathrm{N}=10, \kappa=35.9, \alpha_{95}=7.3^{\circ}\right)($ Figure 7a). Directions for Comp B fall into two groups, one with positive inclinations with a formation mean direction of $D / I=$ $29.3^{\circ} / 16.8^{\circ}\left(\mathrm{N}=4, \kappa=35.7, \alpha_{95}=10.9^{\circ}\right)$, and the other with negative inclinations $(D / I=$ $229.9^{\circ} / 12.8^{\circ}, \mathrm{N}=2, \kappa=45, \alpha_{95}=10.1^{\circ}$ ), which is consistent with previous results from this area (Opdyke et al., 1986; Su et al., 2005) (Figure 7b). Comp B directions pass a reversals test at the 95\% significance level (McFadden and McElhinny, 1990). Although we cannot conduct a fold test because the sampled Huangmaqing Formation red beds are monoclinal, the tilt test (Watson and Enkin, 1993; Enkin, 2003) for Comp B gives a maximum grouping of directions at 144 percent unfolding (Figure S1). All of these observations indicate that Comp $\mathrm{B}$ has a pre-folding origin. Thus, thermal demagnetization is effective for analyzing partially remagnetized red beds with dispersed unblocking temperature spectra. The direction obtained from CD treatment is similar to that identified from TD for Comp A with steep downward-directed inclinations (Figure 7c); however, Comp B cannot be isolated from combined CD-TD treatment (Figure 7d). Our results indicate that $\mathrm{TD}$ is more effective than $\mathrm{CD}$, which raises the question of why $\mathrm{CD}$ is less effective in thesesamples.

Red bed NRMs are generally a composite of a DRM and CRM, where the former is often thought to be carried by rather coarse detrital magnetic minerals (i.e., hematite or 
magnetite), while the latter is recorded by fine-grained hematite pigment (e.g., Collinson, 1974; Larson and Walker, 1975; McClelland, 1996; Iosifidi et al., 2010). Fine-grained hematite pigment is expected to be more soluble than the coarser detrital hematite particles. $\mathrm{HCl}$ leaches all iron oxides, and removes the most soluble grains first leaving less soluble grains behind (Burek, 1969; Park, 1970; Henry, 1979; Tauxe et al., 1980). For example, fine-grained hematite cement has a high propensity to dissolve and, therefore, dissolves readily, leaving behind partially dissolved specularite (Henry, 1979; Cornell and Giovanoli, 1993). This allows identification of the magnetization component carried by detrital specularite. Therefore, CD could be useful when dealing with sediments with multicomponent magnetizations within a single sample, such as a DRM and CRM. However, if the solubility spectra of hematite cement and specularite overlap in some unknown fashion, simple vector subtraction cannot be used to identify the respective components.

IRM unmixing analysis indicates that low- $(\sim 100-200 \mathrm{mT})$ and high-coercivity ( $\sim 500-700 \mathrm{mT})$ components can be separated (Figure 2), which may reflect different particle size distributions of hematite based on the positive relationship of particle size and coercivity. During acid leaching, the coercivities of the two components decrease simultaneously (Figure 4e-f), which indicates a particle size decrease for both components (Hartstra, 1982; Dekkers and Linssen, 1989). Thus, fine and coarse particles both dissolve during this process, so that the paleomagnetic direction identified with $\mathrm{CD}$ is in principle the vector sum of the two components identified from direct TD (Figure 6d, g). Tauxe et al. (1980) conducted chemical leaching on Siwalik red beds in which the dominant magnetic carrier is hematite and found that the bulk remanent coercivity decreases after acid leaching, so they deduced that hematite pigment is magnetically harder than specularite because they assumed that only pigment was dissolved. Our 
results provide a reasonable explanation for the decreased bulk coercivity, where both low and high coercivity components dissolve during acid leaching (Figure 4d-f). Hematite is presumably present in various forms with diverse origins (Walker et al., 1981), which refines the commonly held view that hematite in red beds can be divided into just two groups: pigment and detrital specularite. Authigenic hematite occurs not only as pigment, but also as microcrystalline, polycrystalline, and monocrystalline grains with sizes in the micrometer range (Walker et al., 1981), which will not dissolve as readily as pigment. Therefore, $\mathrm{CD}$ is not so effective in removing secondary hematite with a wide particle size distribution. However, for red bed samples with distinct particle size distributions, such as pigment and specularite, $\mathrm{CD}$ could provide meaningful results (Henry, 1979; Tan et al., 2007).

\subsection{Remagnetization mechanism for the steep magnetization component}

A strong secondary vertically-directed magnetization component is often observed in Triassic samples from South China (Figure 8), including the studied Huangmaqing Formation in Nanjing (Kent et al., 1986, 1987; Opdyke et al., 1986; Su et al., 2005), the Anshun and Huaxi Formations in Guizhou province (Huang and Opdyke, 1996, 2015) and Hubei province (Huang and Opdyke, 1997, 2000), the Badong Formation in the border area between Sichuan, Hubei and Hunan provinces (Huang and Opdyke, 1991, 1992), and the Tongtoujian Formation in Anhui province (Gilder et al., 1999; Su et al., 2005). However, the origin of this component is unclear (Opdyke et al., 1986). Previous studies have proposed that it might represent a multicomponent magnetization that yields a vertical resultant, with overprinting in a post-folding steeply inclined magnetic field (Opdyke et al., 1986) that might be related to late Mesozoic Yanshanian orogenic activity in these parts of South China (Kent et al., 1987; Wang and van der Voo, 1993), which led 
to substantial intracontinental tectonic rotations.

Red bed remagnetization usually results from secondary hematite formation via crystallization from solution or by mineral alteration. For the former mechanism, the CRM can record faithfully the magnetic field direction if it is a single-stage growth process (Stokking and Tauxe, 1987, 1990a; Jiang et al., 2015), while the magnetization direction for the latter mechanism will be controlled by both the remanence of the parent mineral(s) and the ambient magnetic field direction (Heider and Dunlop, 1987; Stokking and Tauxe, 1990b; Madsen et al., 2002). In our experiments, only hematite components with unblocking temperatures between $\sim 650^{\circ} \mathrm{C}$ and $685^{\circ} \mathrm{C}$ are interpreted as a ChRM in the direct TD results (Figure 2). However, based on CD-TD treatment of a three-component IRM, magnetite is detected in the low-coercivity component with a Curie temperature below $600{ }^{\circ} \mathrm{C}$ after $\mathrm{CD}$ (Figure 4a-c); this component is not observed in direct TD results for a three-component IRM because hematite is so dominant ( $\mathrm{Su}$ et al., 2005). A Verwey transition is also more evidentin low-temperature ZFC curves for samples after CD treatment (Figure 5). We deduce that this magnetite is concealed by its small concentration with respect to the large hematite pigment concentration, which precludes its detection by direct TD. Magnetite may also be a parent mineral for secondary hematite.

Paleomagnetic poles for Comp B (Figure 9) cluster alongside those from previous studies and close to the position of Triassic paleomagnetic poles, which further indicates that Comp B is a primary NRM component. However, the paleomagnetic pole for Comp A lies far from the apparent polar wander path of the South China Block (Figure 9), which suggests that the recording of Comp A was controlled not only by the ambient paleomagnetic field, but also by additional factors. Parent magnetic particles can control second-generation particles through magnetostatistic or exchange interactions (Stokking 
and Tauxe, 1990b), which leads to a CRM with a direction intermediate between the ambient magnetic field direction and the parent magnetic mineral direction (Heider and Dunlop, 1987; Stokking and Tauxe, 1990b). Late Mesozoic Yanshanian orogenic activity occurred pervasively in the South China Block. Previous studies indicate that the studied Zijinshan hill formed during the Yanshanian orogeny (Xue et al., 1985; Ge, 1987); the fluids produced could have caused conditions required for magnetite oxidation (Kent et al., 1987). In addition, the stress field of an orogeny can play a role in CRM acquisition by deviating it from the ambient field direction (Nagata, 1970; Gilder, 2007). Therefore, we suggest that the direction of the secondary component was controlled by several factors. Before the orogenic activity and diagenesis, the paleomagnetic field is inferred to have been recorded faithfully by Comp B, which is carried by detrital magnetite and hematite. However, during or after tectonic activity, the accompanying temperature increase would have promoted magnetite oxidation. During this process, a tectonically rotated parent remanence carried by magnetite with the influence of a contemporaneous ambient geomagnetic field and stress field generated by tectonic activity are argued to have produced the steep downward-directed magnetization in the studied samples. We suggest that this is why a steep magnetization component is commonly observed in different areas of the South China Block.

\section{Conclusions}

Based on systematic thermal and chemical demagnetization, and rock magnetic analysis, thermal demagnetization is more effective in isolating an apparently primary magnetization than chemical demagnetization in red beds from South China. Two remanence components carried by secondary and primary hematite are isolated with thermal demagnetization, where the latter records a paleomagnetic direction that is 
consistent with published results. However, chemical demagnetization fails to extract a

421 ChRM direction from the remagnetized component due to simultaneous dissolution of

422 both fine and coarser hematite particles.

The presence of magnetite provides clues to the remagnetization mechanism in these samples. The CRM carried by secondary hematite is interpreted to have been generated by magnetite oxidation during tectonic activity. Therefore, the secondary magnetization with steep inclination,which is observed commonly in Triassic samples from different areas of the South China Block, is interpreted to have been influenced by a combination of the remanence carried by parent magnetite, the orogenic stress field, and the contemporaneous geomagnetic field direction during deformation. Our results shed new light on interpretation of paleomagnetic results from remagnetized red beds and are significant for tectonic studies of southern China.

\section{Acknowledgements}

We thank Dr. Yonggang Yan, Zhiyu Yi, and Shuhui Cai for useful discussions about this work. This study was supported bythe National Program on Global Change and Air-Sea Interaction (GASI-04-01-02), the National Natural Science Foundation of China (grants 41430962, 41374073, and 41504055), and Chinese Continental Shelf Deep Drilling Program (GZH201100202). Z.X.J. further acknowledges support from the China Postdoctoral Science Foundation. A.P.R. acknowledges support from the Australian Research Council (grant DP120103952).

\section{References}

Achache, J., Courtillot, V., Xiu, Z.Y., 1984. Paleogeographic and tectonic evolution of southern Tibet since middle Cretaceous time: new paleomagnetic data and 
synthesis. J. Geophys. Res. 89, 10311-10339.

Burek, P.J., 1969. Device for chemical demagnetization of red beds. J. Geophys. Res. 74, $6710-6712$.

Butler, R.F., 1992. Paleomagnetism: Magnetic Domains to Geologic Terranes, Blackwell.

Collinson, D., 1965.The remanent magnetization and magnetic properties of red sediments.Geophys. J. R. Astron. Soc. 10, 105-126.

Collinson, D., 1974. The role of pigment and specularite in the remanent magnetism of red sandstones. Geophys. J. R. Astron. Soc. 38, 253-264.

Collinson, D.W., 1975. Instruments and techniques in paleomagnetism and rock magnetism. Rev. Geophys. 13, 659-686.

Cornell, R., Giovanoli, R., 1993. Acid dissolution of hematites of different morphologies. Clay Miner. 28, 223-232.

Creer, K., 1961.Superparamagnetism in red sandstones. Geophys. J. R. Astron. Soc. 5, $16-28$.

Creer, K., 1968. Palaeozoic palaeomagnetism. Nature 219, 246-250.

Dekkers, M.J., 2012. End-member modelling as an aid to diagnose remagnetization: a brief review. Geol. Soc. Lond. Spec. Publ. 371, 253-269.

Dekkers, M., Linssen, J., 1989. Rockmagnetic properties of fine-grained natural low-temperature haematite with reference to remanence acquisition mechanisms in red beds.Geophys.J. Int. 99, 1-18.

Deng, C., Liu, Q., Wang, W., Liu, C., 2007. Chemical overprint on the natural remanent magnetization of a subtropical red soil sequence in the Bose Basin, southern China. Geophys. Res. Lett. 34, L22308, doi:22310.21029/22007GL031400.

Dobson, J.P., Heller, F., 1992. Remagnetization in southeast China and the collision and suturing of the Huanan and Yangtze Blocks. Earth Planet. Sci. Lett. 111, 11-21. 
Dunlop, D.J., Özdemir, Ö., 1997. Rock Magnetism: Fundamentals and Frontiers, Cambridge University Press.

Elmore, R.D., Muxworthy, A.R., Aldana, M., 2012.Remagnetization and chemical alteration of sedimentary rocks.Geol. Soc. Lond. Spec. Publ.371, 1-21.

Enkin, R., Courtillot, V., Leloup, P., Yang, Z., Xing, L., Zhang, J.,Zhuang, Z., 1992. The paleomagnetic record of uppermost Permian, Lower Triassic rocks from the South China Block. Geophys. Res.Lett.19, 2147-2150.

Enkin, R.J., 2003. The direction-correction tilt test: an all-purpose tilt/fold test for paleomagnetic studies. Earth Planet. Sci.Lett.212, 151-166.

Fisher, R., 1953. Dispersion on a sphere. Proc. R. Soc. Lond. A 217, 295-305.

Ge, X.H., 1987. Nappe structures in the Ningzhen Mountains. J. Changchun College Geol. (in Chinese) 17, 143-154.

Gilder, S., 2007. Magnetization, piezoremanence and stress demagnetization, In: Gubbins, D., Herrero-Bervera, E., eds. Encyclopedia of Geomagnetism and Paleomagnetism.Springer, 2599-2603.

Gilder, S.A., Leloup, P.H., Courtillot, V., Chen, Y., Coe, R.S., Zhao, X., Xiao, W., Halim, N., Cogné, J.P., Zhu, R., 1999. Tectonic evolution of the Tancheng-Lujiang (Tan-Lu) fault via middle Triassic to Early Cenozoic paleomagnetic data. J. Geophys. Res. 104, 15365-15390.

Globokar, D.M., 2014. Testing thermal viscous remanent magnetization (TVRM) as a tool to date geomorphic events. MS thesis. University of Washington.

Hartstra, R.L., 1982. Some rock magnetic parameters for natural iron-titanium oxides. $\mathrm{PhD}$ thesis. University of Utrecht.

Hashimoto, T., Hurst, T., Suzuki, A., Mogi, T., Yamaya, Y., Tamura, M., 2008. The role of thermal viscous remanent magnetisation (TVRM) in magnetic changes 
associated with volcanic eruptions: insights from the 2000 eruption of Mt Usu, Japan. J. Volcanol.Geotherm.Res. 176, 610-616.

497

Heider, F., Dunlop, D.J., 1987. Two types of chemical remanent magnetization during the oxidation of magnetite. Phys. Earth Planet. Inter. 46, 24-45.

Henry, S.G., 1979. Chemical demagnetization: methods, procedures, and applications through vector analysis. Can. J. Earth Sci. 16, 1832-1841.

Heslop, D., Dekkers, M., Kruiver, P., Van Oorschot, I., 2002. Analysis of isothermal remanent magnetization acquisition curves using the expectation-maximization algorithm. Geophys. J. Int. 148, 58-64.

Hu, P., Liu, Q., Torrent, J., Barrón, V., Jin, C., 2013. Characterizing and quantifying iron oxides in Chinese loess/paleosols: implications for pedogenesis. Earth Planet. Sci. Lett. 369-370, 271-283.

Huang, K., Opdyke, N.D., 1991. Paleomagnetism of Jurassic rocks from southwestern Sichuan and the timing of the closure of the Qinling suture. Tectonophysics 200, 299-316.

Huang, K., Opdyke, N.D., 1992. Paleomagnetism of Cretaceous to lower Tertiary rocks from southwestern Sichuan: a revisit. Earth Planet. Sci. Lett. 112, 29-40.

Huang, K., Opdyke, N.D., 1996. Severe remagnetization revealed from Triassic platform carbonates near Guiyang, Southwest China. Earth Planet. Sci. Lett. 143, 49-61.

Huang, K., Opdyke, N.D., 1997. Middle Triassic paleomagnetic results from central Hubei province, China and their tectonic implications. Geophys. Res. Lett. 24, $1571-1574$.

Huang, K., Opdyke, N.D., 2000. Magnetostratigraphic investigations of the Middle Triassic Badong Formation in South China. Geophys. J. Int. 142, 74-82. 
Huang, K., Opdyke, N.D., 2015. Post-folding magnetization of the Triassic rocks from western Guizhou and southern Yunnan provinces: new evidence for large clockwise rotations in the Simao Terrane. Earth Planet. Sci. Lett. 423, 155-163.

Iosifidi, A.G., Mac Niocaill, C., Khramov, A.N., Dekkers, M.J., Popov, V.V., 2010. Palaeogeographic implications of differential inclination shallowing in Permo-Carboniferous sediments from the Donets basin, Ukraine. Tectonophysics 490, 229-240.

Jiang, Z.X., Liu, Q., Barrón, V., Torrent, J., Yu, Y., 2012. Magnetic discrimination between Al-substituted hematites synthesized by hydrothermal and thermal dehydration methods and its geological significance. J. Geophys. Res. 117, B02102, doi:02110.01029/02011JB008605.

Jiang, Z.X., Liu, Q., Dekkers, M.J., Colombo, C., Yu, Y., Barrón, V., Torrent, J., 2014. Ferro and antiferromagnetism of ultrafine-grained hematite. Geochem. Geophys. Geosyst. 15, 2699-2712.

Jiang, Z.X., Liu, Q., Dekkers, M.J., Tauxe, L., Qin, H., Barrón, V., Torrent, J., 2015. Acquisition of chemical remanent magnetization during experimental ferrihydrite-hematite conversion in Earth-like magnetic field - implications for paleomagnetic studies of red beds. Earth Planet. Sci. Lett. 428, 1-10.

Jin, C., Liu, Q., 2011. Remagnetization mechanism and a new age model for L9 in Chinese loess. Phys. Earth Planet. Inter. 187, 261-275.

Katz, B., Elmore, R.D., Cogoini, M., Engel, M.H., Ferry, S., 2000.Associations between burial diagenesis of smectite, chemical remagnetization, and magnetite authigenesis in the Vocontian trough, SE France. J.Geophys.Res. 105, 851-868. 
Kent, D.V., Opdyke, N.D., 1978. Paleomagnetism of the Devonian Catskill red beds: evidence for motion of the coastal New England-Canadian maritime region relative to cratonic North America. J. Geophys. Res. 83, 4441-4450.

Kent, D.V., 1985. Thermoviscousremagnetization in some Appalachian limestones.Geophys. Res.Lett.12, 805-808.

Kent, D.V., Xu, G., Huang, K., Zhang, W., Opdyke, N.D., 1986. Paleomagnetism of upper Cretaceous rocks from South China. Earth Planet. Sci. Lett. 79, 179-184.

Kent, D.V., Zeng, X., Zhang, W.Y., Opdyke, N.D., 1987. Widespread late Mesozoic to Recent remagnetization of Paleozoic and lower Triassic sedimentary rocks from South China. Tectonophysics 139, 133-143.

Kirschvink, J.L., Kopp, R.E., Raub, T.D., Baumgartner, C.T., Holt, J.W., 2008. Rapid, precise, and high-sensitivity acquisition of paleomagnetic and rock-magnetic data: development of a low-noise automatic sample changing system for superconducting rock magnetometers. Geochem. Geophys. Geosyst. 9, Q05Y01, doi:10.1029/2007GC001856.

Kruiver, P.P., Dekkers, M.J., Heslop, D.,2001. Quantification of magnetic coercivity components by the analysis of acquisition curves of isothermal remanent magnetisation. Earth Planet. Sci.Lett. 189, 269-276.

Larson, E.E., 1981. Selective destructive demagnetization-another microanalytic technique in rock magnetism. Geology 9, 350-355.

Larson, E.E., Walker, T.R., 1975.Development of chemical remanent magnetization during early stages of red-bed formation in Late Cenozoic sediments, Baja California. Geol. Soc. Am.Bull.86, 639-650.

Liu, C., Ge, K., Zhang, C., Liu, Q., Deng, C., Zhu, R., 2011. Nature of remagnetization of Lower Triassic red beds in southwestern China. Geophys. J. Int. 187, 1237-1249. 
567

568

569

Lowrie, W., 1990. Identification of ferromagnetic minerals in a rock by coercivity and unblocking temperature properties. Geophys. Res. Lett. 17, 159-162.

Lu, G., McCabe, C., Henry, D.J., Schedl, A., 1994. Origin of hematite carrying a Late Paleozoic remagnetization in a quartz sandstone bed from the Silurian Rose Hill Formation, Virginia, USA. Earth Planet. Sci. Lett. 126, 235-246.

Madsen, K.N., Walderhaug, H., Torsvik, T., 2002. Erroneous fold tests as an artifact of alteration chemical remanent magnetization. J. Geophys. Res. 107, doi:10.1029/2001JB000805.

McCabe, C., Elmore, R.D., 1989. The occurrence and origin of Late Paleozoic remagnetization in the sedimentary rocks of North America. Rev. Geophys. 27, $471-494$.

McClelland-Brown, E., 1982. Discrimination of TRM and CRM by blocking-temperature spectrum analysis. Phys. Earth Planet. Inter. 30, 405-414.

McClelland, E., 1996. Theory of CRM acquired by grain growth, and its implications for TRM discrimination and palaeointensity determination in igneous rocks. Geophys. J. Int. 126, 271-280.

McFadden, P., McElhinny, M., 1990.Classification of the reversal test in palaeomagnetism.Geophys. J. Int.103, 725-729.

Nagata, T., 1970.Effects of a uniaxial compression on remanent magnetizations of igneous rocks.Pure Appl. Geophys.78, 100-109.

Opdyke, N.D., Huang, K., Xu, G., Zhang, W., Kent, D.V., 1986. Paleomagnetic results from the Triassic of the Yangtze Platform. J. Geophys. Res. 91, 9553-9568. 
Park, J.K., 1970. Acid leaching of red beds and the relative stability of the red and black magnetic components. Can. J. Earth Sci. 7, 1086-1092.

Piper, J.D.A., Thomas, D.N., Share, S., Rui, Z.Q., 1999. The palaeomagnetism of (Mesoproterozoic) Eriksfjord Group red beds, South Greenland: multiphase remagnetization during the Gardar and Grenville episodes. Geophys. J. Int. 136, 739-756.

Roberts, A.P., 2015. Magnetic mineral diagenesis. Earth-Sci. Rev. 151, 1-47.

Roberts, A.P., Weaver, R., 2005. Multiple mechanisms of remagnetization involving sedimentary greigite $\left(\mathrm{Fe}_{3} \mathrm{~S}_{4}\right)$. Earth Planet. Sci. Lett. 231, 263-277.

Rowan, C.J., Roberts, A.P., 2006. Magnetite dissolution, diachronous greigite formation, and secondary magnetizations from pyrite oxidation: unravelling complex magnetizations in Neogene marine sediments from New Zealand. Earth Planet. Sci. Lett. 241, 119-137.

Scotese, C.R., Van derVoo, R., McCabe, C., 1982.Paleomagnetism of the Upper Silurian and Lower Devonian carbonates of New York State: evidence for secondary magnetizations residing in magnetite. Phys. Earth Planet.Inter.30, 385-395.

Steiner, M.B., Lucas, S.G., 2000. Paleomagnetism of the Late Triassic Petrified Forest Formation, Chinle Group, western United States: further evidence of "large" rotation of the Colorado Plateau. J. Geophys. Res. 105, 25,791-25,808.

Stokking, L.B., Tauxe, L., 1987. Acquisition of chemical remanent magnetization by synthetic iron oxide. Nature 327, 610-612.

Stokking, L., Tauxe, L., 1990a. Properties of chemical remanence in synthetic hematite: 
612

Stokking, L.B., Tauxe, L., 1990b. Multicomponent magnetization in synthetic hematite. Phys. Earth Planet. Inter. 65, 109-124.

Su, L., Yang, Z., Sun, Z., Yang, T., Zaman, H., Takemoto, K., Otofuji, Y., 2005. Regional deformational features of the South China Block inferred from Middle Triassic palaeomagnetic data. Geophys. J. Int. 162, 339-356.

Sugimoto, T., Muramatsu, A., Sakata, K., Shindo, D., 1993.Characterization of hematite particles of different shapes.J. Colloid Interface Sci. 158, 420-428.

Sugimoto, T., Itoh, H., Mochida, T., 1998. Shape control of monodisperse hematite particles by organic additives in the gel-sol system. J. Colloid Interface Sci. 205, $42-52$.

Sun, Z., Yang, Z., Pei, J., Yang, T., Wang, X., 2006. New Early Cretaceous paleomagnetic data from volcanic and red beds of the eastern Qaidam Block and its implications for tectonics of Central Asia. Earth Planet. Sci. Lett. 243, 268-281.

Tan, X., Kodama, K.P., Gilder, S., Courtillot, V., 2007. Rock magnetic evidence for inclination shallowing in the Passaic Formation red beds from the Newark basin and a systematic bias of the Late Triassic apparent polar wander path for North America. Earth Planet. Sci. Lett. 254, 345-357.

Tauxe, L., Kent, D.V., Opdyke, N.D., 1980. Magnetic components contributing to the NRM of Middle Siwalik red beds. Earth Planet. Sci. Lett. 47, 279-284.

Van der Voo, R., Torsvik, T.H., 2012. The history of remagnetization of sedimentary rocks: deceptions, developments and discoveries. Geol. Soc. Lond. Spec. Publ. $371,23-53$. 
Walker, T.R., Larson, E.E., Hoblitt, R.P., 1981. Nature and origin of hematite in the Moenkopi Formation (Triassic), Colorado Plateau: a contribution to the origin of magnetism in red beds. J. Geophys. Res. 86, 317-333.

Wang, Z., Van der Voo, R., 1993. Pervasive remagnetization of Paleozoic rocks acquired at the time of Mesozoic folding in the South China Block. J. Geophys. Res. 98, $1729-1741$.

Watson, G.S., Enkin, R.J., 1993. The fold test in paleomagnetism as a parameter estimation problem. Geophys. Res. Lett. 20, 2135-2137.

Weaver, R., Roberts, A.P., Barker, A.J., 2002. A late diagenetic (synfolding) magnetization carried by pyrrhotite: implications for paleomagnetic studies from magnetic iron sulphide-bearing sediments. Earth Planet. Sci. Lett. 200, 371-386.

Xue, H., Shi, H.S., Xu, G.Q., 1985. Nappe structure and folds on Nanjing-Zhenjiang mountain range. Bull. Nanjing Inst. Geol. M.R., Chinese Acad. Geol. Sci. 6, 1-14.

Yang, Z., Besse, J., 2001. New Mesozoic apparent polar wander path for south China: tectonic consequences. J.Geophys.Res. 106, 8493-520.

Zaman, H., Torii, M., 1999. Palaeomagnetic study of Cretaceous red beds from the eastern Hindukush ranges, northern Pakistan: palaeoreconstruction of the Kohistan-Karakoram composite unit before the India-Asia collision. Geophys. J. Int. 136, 719-738.

Zijderveld, J.D.A., 1967. A.C. demagnetization of rocks: analysis of results. In: Methods in Palaeomagnetism, Collinson, D.W., Creer, K.M., Runcorn, S.K., eds. Elsevier, $254-286$. 
Figure 1. (a) Geological map of the study area in Nanjing, where the inset is a tectonic sketch map of South China (NCB and SCB represent North China Block and South China Block, respectively). The star denotes the locality sampled inthis study. Abbreviations: $\mathrm{Q}=$ Quaternary; $\mathrm{K}=$ Cretaceous; $\mathrm{J}=$ Jurassic; $\mathrm{T}=$ Tertiary; $\mathrm{T}_{2} \mathrm{~h}=$ Huangmaqing formation; $\mathrm{T}_{2} \mathrm{x}=$ Xujiashan formation; $\delta \mu_{5}=$ diorite porphyrite; $\eta о \pi=$

Quartz monzonitic porphyry. (b) Representative photograph of the sampled section with strike/dip orientation of strata of $200^{\circ} / 21^{\circ}$. (c) Oriented samples prior to chemical demagnetization with $0.5-\mathrm{mm}$ drill holes in their surfaces. (d) Oriented samples after chemical demagnetization.

668

Figure 2. Magnetic characteristics of three typical groups of red bed samples. (a-1)/(b-1)/(c-1) Orthogonal vector demagnetization plots (Zijderveld, 1967) withstepwise thermal demagnetization data for representative samples, where solid and open circles represent horizontal and vertical projections, respectively. The inset in each subfigure is azoom of the orthogonal plot from $\sim 650$ to $690{ }^{\circ} \mathrm{C}$. (a-2)/(b-2)/(c-2) Hysteresis loops after paramagnetic slope correction for representative samples. (a-3)/(b-3)/(c-3) IRM component analysis, where orange, blue, and purple lines indicate where the purple and blue lines indicate heating and cooling cycles, respectively.

Figure 3. Normalizedstepwise thermal decaycurves for representative samples, where the 
shaded area represents the range of values from the model of Jiang et al. (2015) to discriminatebetween a chemical remanent magnetization (CRM) and a detrital remanent magnetization (DRM).

Figure 4. The response of three IRM coercivityfractionsto chemical-thermal demagnetization. (a-c) Progressive chemical-thermal demagnetization of a three-component IRM produced by magnetizing samples in $0.05,0.5$, and $2.5 \mathrm{~T}$ fields that were applied along the $\mathrm{X}$ (open circles), $\mathrm{Y}$ (solid circles), and Z sample axes (solid cross), respectively. (d-f) Coercivity variations during chemical demagnetization, where $B_{\mathrm{cr}}$ is for the bulk sample, and $B_{\mathrm{L} 1 / 2}$ and $B_{\mathrm{H} 1 / 2}$ are identified from IRM component fitting (Kruiver et al., 2001).

Figure 5. Representativezero-field cooled (ZFC) warming curves forthe three identified groupsof samples before and after CD treatment. (a-c) ZFC curves for typical samples (NJ16-8, NJ7-8, and NJ12-9) before CD treatment; (d-f) ZFC curves for typical samples (NJ16-8, NJ7-8, and NJ12-9) after CD treatment. Dashed lines are derivatives of the ZFC warming curves.

Figure 6. Comparison of direct thermal demagnetization results (black symbols) and chemical demagnetization (light grey) followed by thermal demagnetization (dark grey) results for representative samples. (a, d, g) Orthogonal vector demagnetization plots; (b, e, h) equal area stereographic projections of stepwise demagnetization data; and (c, f, i) 
NRM decay curves (normalized vector differences) for chemical demagnetization and subsequent thermal demagnetization treatments.

Figure 7. Stereographic projections for the directions of (a) component A (Comp A) and (b) component B (Comp B) acquired after direct thermal demagnetization, and (c, d) Comp A and B after combined chemical and thermal demagnetization (CD-TD). The sky-blue solid circles represent mean paleomagnetic directions for each site, while the ellipses indicate $95 \%$ confidence intervals about each mean. The red symbols in (b) represent reference data from Su et al. (2005) for the study area.

Figure 8. Stereographic projections for the directions of the remagnetized component from different areas of South China. The sky-blue solid circles represent mean directions for each site, while the ellipses indicate $95 \%$ confidence intervals about each mean.

Figure 9. Equal area projection of Middle Triassic paleomagnetic poles (yellow solid circles) with associated 95\% confidence ellipses for the South China Block (SCB) (I: Tongling, Su et al. (2005); II: Nanjing, this study; III: Nanjing, Su et al. (2005); IV: Nanzhang, Su et al. (2005); V: Jingme-Dagyang, Huang and Opdyke (1997); VI: Nanjing, Opdyke et al. (1986)). Black solid circles represent the apparent polar wander path for the SCB from Yang and Besse (2001) and Enkin et al. (1992): P2 = Late Permian; T1 = Early Triassic; $\mathrm{T} 3$ = Late Triassic; J1 = Early Jurassic; J3 = Late Jurassic; K1 = Early Cretaceous; $\mathrm{K} 2$ = Late Cretaceous; $\mathrm{E}=$ Eogene; $\mathrm{N}=$ Neogene. Purple solid circles represent the paleomagnetic pole for Comp A from this and previous studies. 
Table 1. Site and formation statistics for the Huangmaqing Formation from Nanjing ${ }^{\mathrm{a}}$.

$736{ }^{\mathrm{a}}$ Bedding is strike/dip (in degrees), while $\mathrm{B}$ and $\mathrm{A}$ represent components $\mathrm{B}$ and A, 737 respectively. $n / N$ is the number of samples used/number of samples measured. $D, I$ are 738 the declination and inclination, respectively. $\alpha_{95}$ is the radius of the $95 \%$ confidence circle about the mean direction. $k_{s}$ is the Fisher (1953) precision parameter after bedding 740 tilt correction.

Table 2. Coercivity variation summary for IRM components from Group I, II, and III samples after each chemical leaching step ${ }^{\mathrm{a}}$. ${ }^{\mathrm{a}} B_{\text {cr }}$ is the bulk remanent coercivity (in $\mathrm{mT}$ ) determined from back field demagnetization curves. $B_{\mathrm{H} 1 / 2}$ and $B_{\mathrm{L} 1 / 2}$ represent the coercivity of the magnetic 'hard' and 'soft' components, respectively (both in $\mathrm{mT}$ ), identified from IRM analysis. 

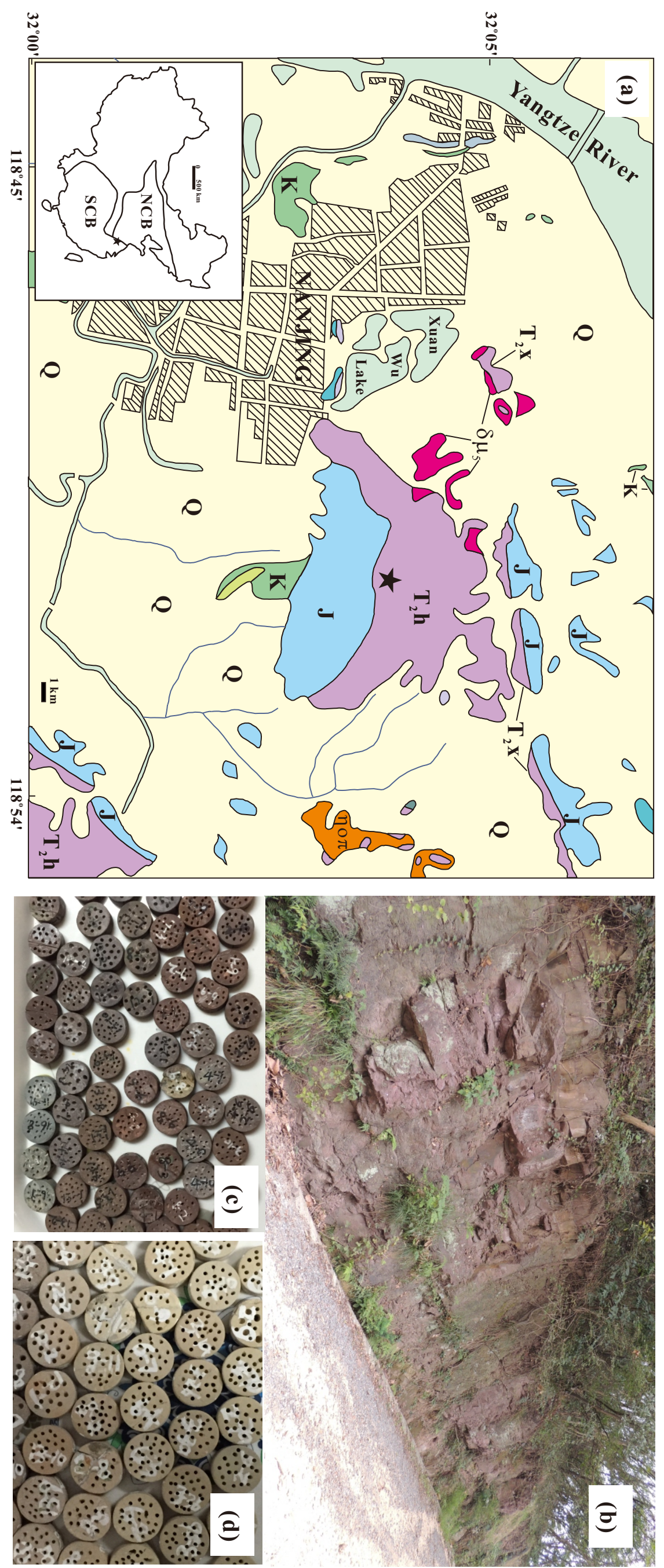

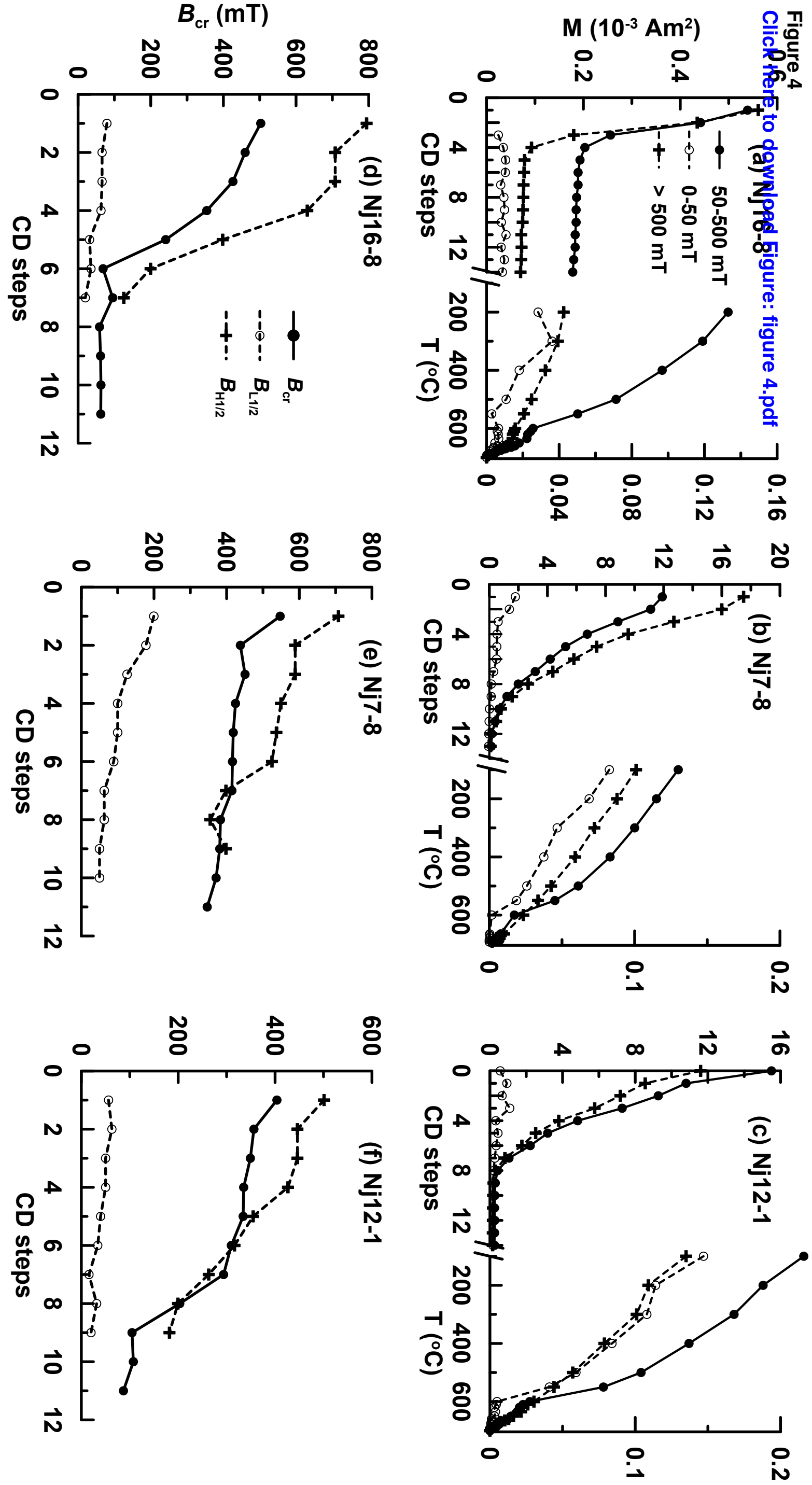

$M\left(10^{-3} \mathrm{Am}^{2}\right)$ 
samples after CD treatment
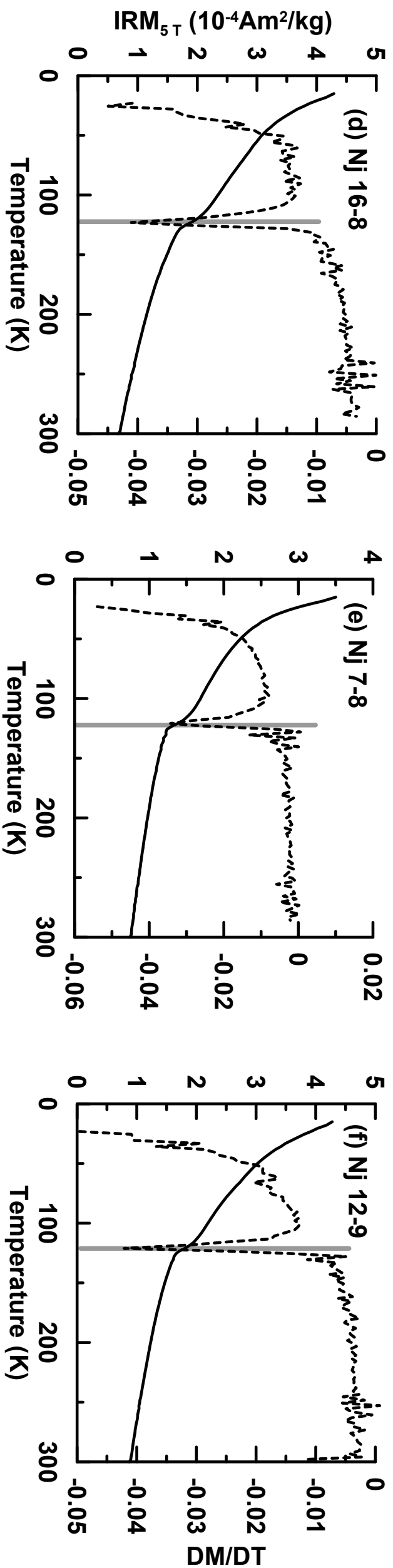

samples before $C D$ treatment
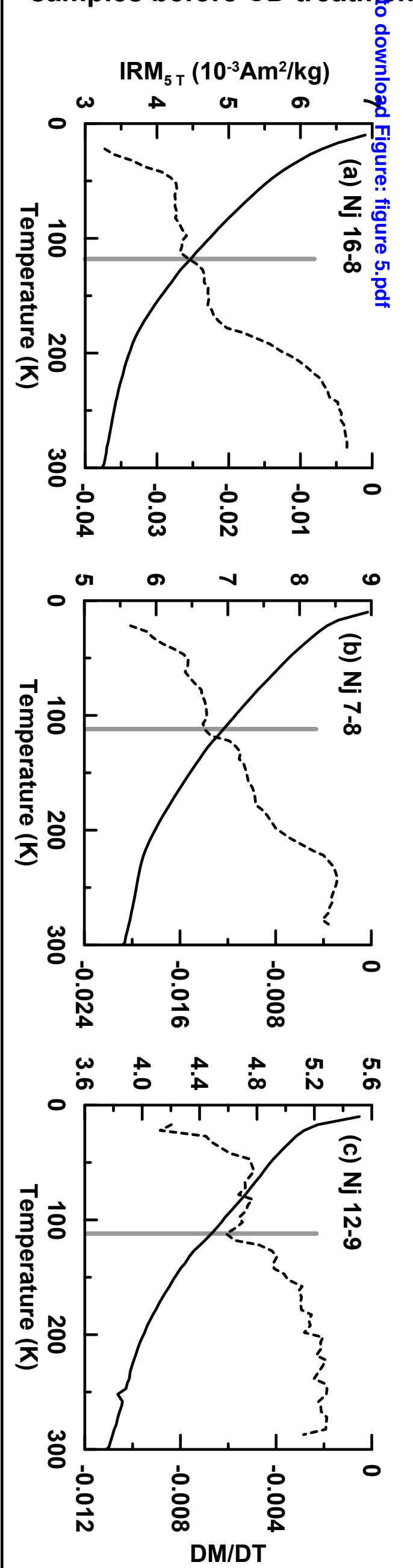

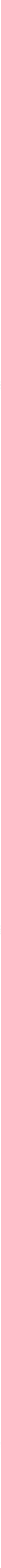


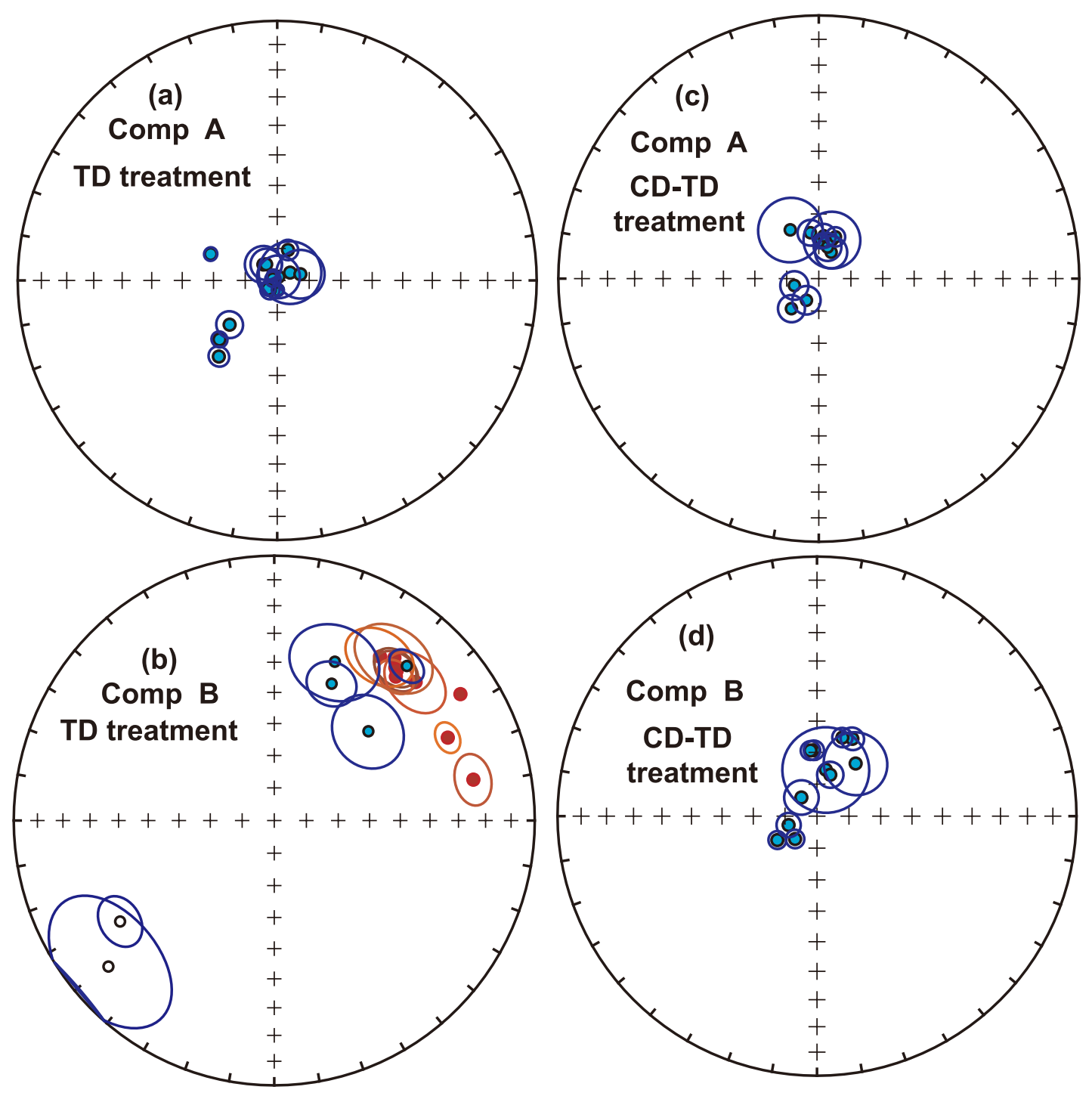




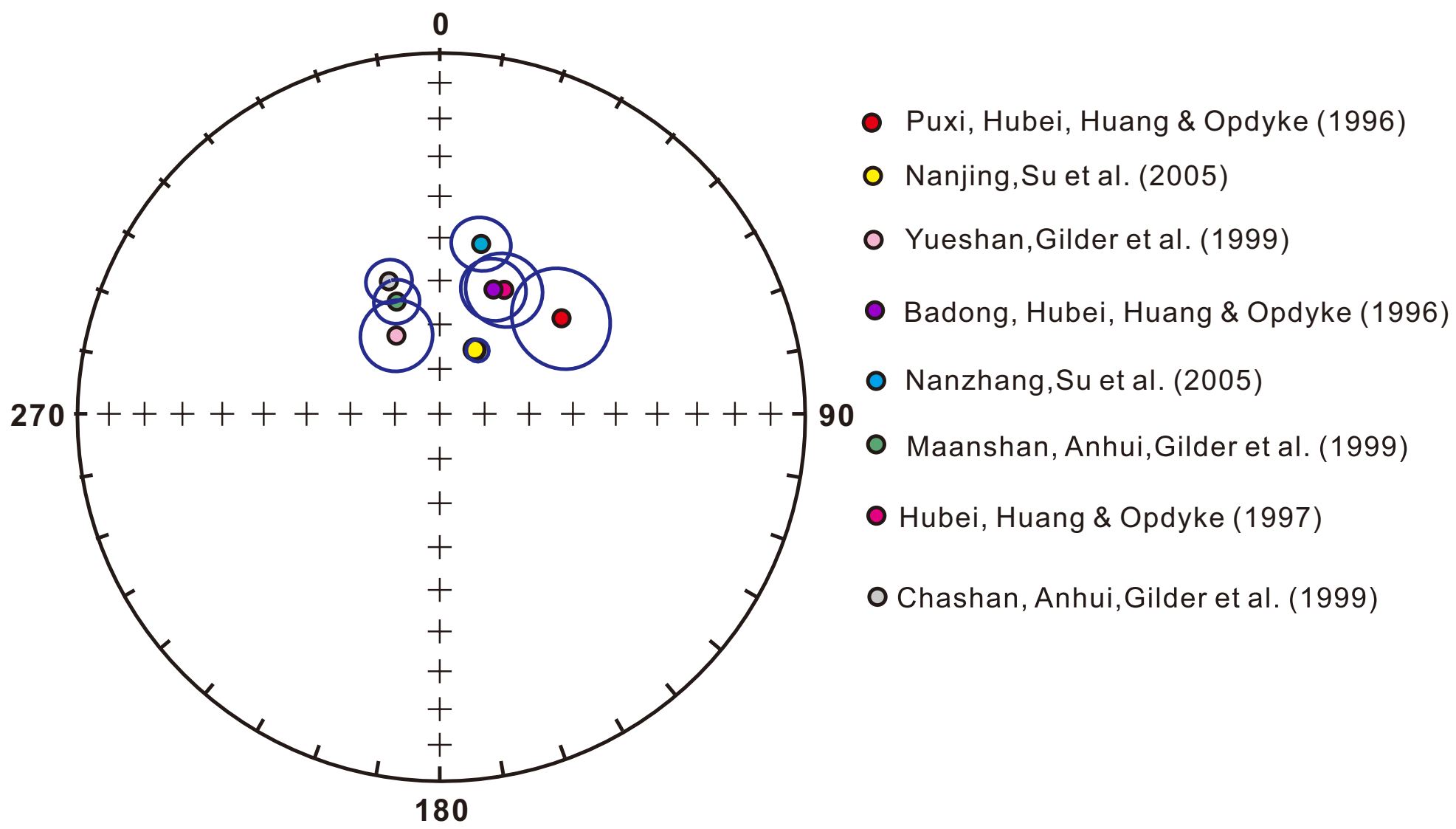




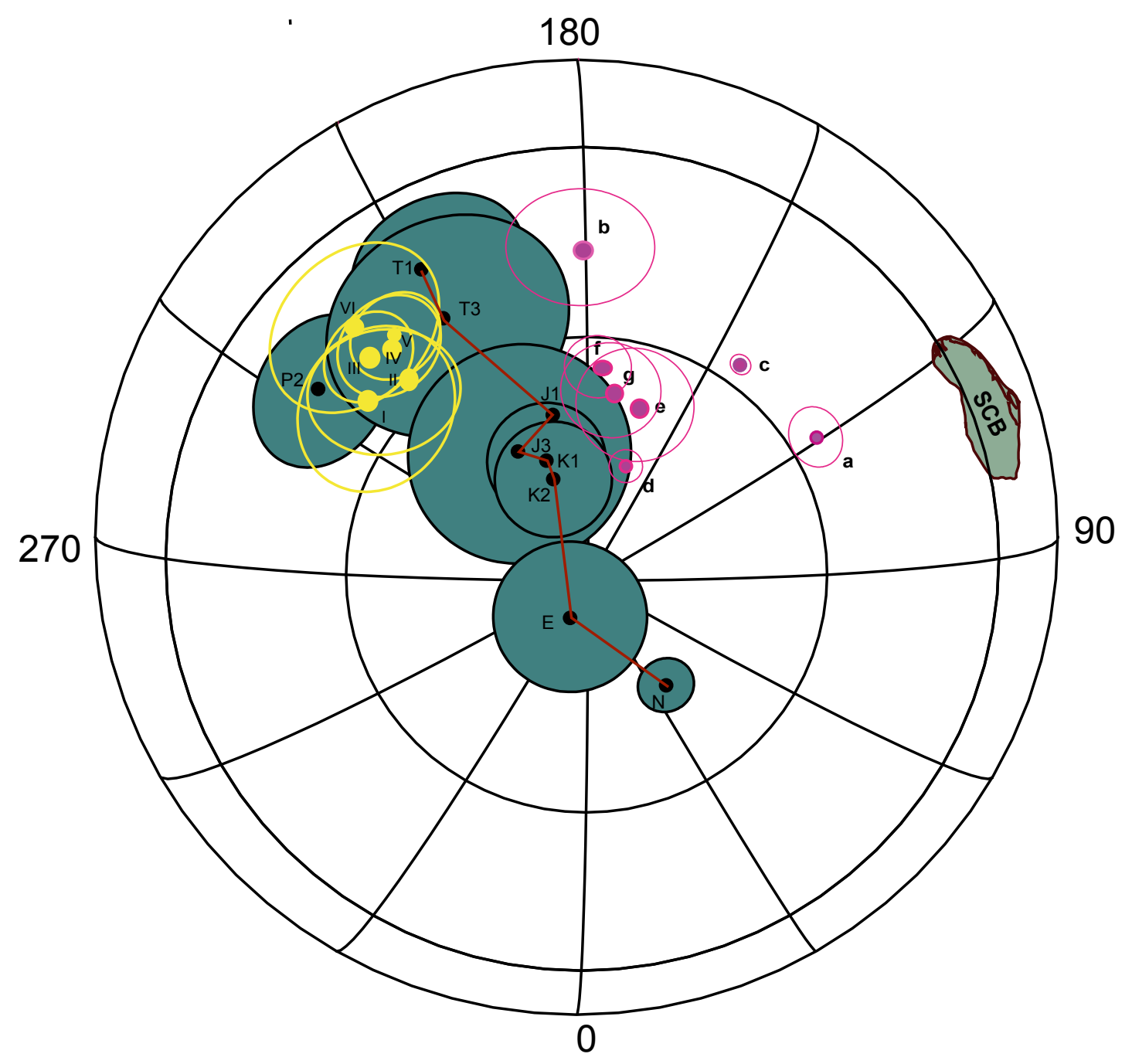


Table 1. Site and formation statistics for the Huangmaqing Formation from Nanjing ${ }^{\mathrm{a}}$.

\begin{tabular}{|c|c|c|c|c|c|c|c|c|c|c|}
\hline \multirow[b]{2}{*}{ Site } & \multirow[b]{2}{*}{ Bedding } & \multirow[b]{2}{*}{ Group } & \multirow{2}{*}{$\begin{array}{c}\text { ChRM } \\
\text { type }\end{array}$} & \multirow[b]{2}{*}{$\mathrm{n} / \mathrm{N}$} & \multicolumn{2}{|c|}{ In situ } & \multicolumn{2}{|c|}{ Tilt corrected } & \multirow[b]{2}{*}{$k_{s}$} & \multirow[b]{2}{*}{$\alpha_{95}$} \\
\hline & & & & & $\mathrm{D}_{\mathrm{g}}$ & $\mathrm{I}_{\mathrm{g}}$ & $\mathrm{D}_{\mathrm{s}}$ & $\mathrm{I}_{\mathrm{s}}$ & & \\
\hline $\mathrm{NJ} 2$ & $201 / 14$ & $\mathrm{I}$ & A & $9 / 9$ & 260.7 & 80.1 & 225.5 & 69.3 & 205.4 & 3.6 \\
\hline NJ3 & $221 / 19$ & I & A & $10 / 10$ & 222.8 & 82.6 & 221.5 & 63.6 & 646.8 & 1.9 \\
\hline NJ4 & $200 / 21$ & I & A & $10 / 10$ & 241.3 & 77.4 & 216 & 58.5 & 192.3 & 3.2 \\
\hline \multirow[t]{2}{*}{ NJ6 } & $252 / 20$ & III & A & $6 / 6$ & 351.2 & 75.7 & 291.6 & 67.5 & 718.7 & 2.1 \\
\hline & & & B & $6 / 6$ & 33.3 & 28.6 & 23.1 & 43.2 & 85.2 & 7.3 \\
\hline \multirow[t]{2}{*}{ NJ7 } & $190 / 16.5$ & II & A & $6 / 6$ & 6.5 & 77.4 & 201 & 86 & 664.6 & 2.6 \\
\hline & & & B & $6 / 6$ & 231.9 & -18.5 & 237.2 & -30.3 & 45 & 10.1 \\
\hline \multirow[t]{2}{*}{ NJ8 } & $202 / 11$ & II & A & $8 / 8$ & 13.7 & 79.1 & 277.4 & 88.6 & 255 & 4.8 \\
\hline & & & B & $8 / 8$ & 228 & -7.1 & 229.1 & -16.9 & 24.6 & 18.9 \\
\hline \multirow[t]{2}{*}{ NJ12 } & $193 / 22$ & III & A & $9 / 9$ & 17.3 & 72.5 & 176.5 & 85.3 & 454.5 & 2.6 \\
\hline & & & B & $9 / 9$ & 38 & 29.9 & 47 & 49.1 & 67.9 & 11.2 \\
\hline \multirow[t]{2}{*}{ NJ13 } & $173 / 22$ & III & A & $10 / 10$ & 19.3 & 71.4 & 115.5 & 80.4 & 460.8 & 2.6 \\
\hline & & & B & $9 / 10$ & 16.8 & 16.1 & 21.2 & 35.9 & 12.8 & 10.8 \\
\hline NJ14 & $227 / 10$ & I & A & $8 / 8$ & 21.1 & 75.7 & 342.1 & 83.1 & 50.1 & 7.9 \\
\hline \multirow[t]{2}{*}{ NJ15 } & $187 / 22$ & III & A & $8 / 8$ & 24.3 & 75.5 & 159.1 & 80.8 & 251.8 & 5.8 \\
\hline & & & B & $8 / 8$ & 38 & 5 & 41.1 & 23.6 & 226 & 5.1 \\
\hline NJ16 & $187 / 22$ & I & A & $10 / 10$ & 338.3 & 80.5 & 227.1 & 80.8 & 59.7 & 6.3 \\
\hline mean & CompA & & & & 355.1 & 80.5 & 227.1 & 80.8 & 35.9 & 7.3 \\
\hline \multirow[t]{2}{*}{ mean } & CompB & & & & 29.3 & 16.8 & 29.2 & 34.6 & 35.7 & 10.9 \\
\hline & & & & & 229.9 & -12.8 & 232.9 & -23.7 & 56.1 & 10.1 \\
\hline
\end{tabular}

${ }^{\mathrm{a}}$ Bedding is strike/dip (in degrees), while $\mathrm{B}$ and $\mathrm{A}$ represent components $\mathrm{B}$ and $\mathrm{A}$, respectively. $n / N$ is the number of samples used/number of samples measured. $D, I$ are the declination and inclination, respectively. $\alpha_{95}$ is the radius of the $95 \%$ confidence circle about the mean direction. $k_{s}$ is the Fisher (1953) precision parameter after bedding tilt correction. 
Table 2. Coercivity variation summary for IRM components from Group I, II, and III samples after each chemical leaching step ${ }^{\mathrm{a}}$.

\begin{tabular}{|c|c|c|c|c|c|c|c|c|c|}
\hline \multirow{2}{*}{ CD step } & \multicolumn{3}{|c|}{ NJ16-8 } & \multicolumn{3}{|c|}{ NJ12-1 } & \multicolumn{3}{|c|}{ NJ7-8 } \\
\hline & $B_{\mathrm{cr}}$ & $B_{\mathrm{L} 1 / 2}$ & $B_{\mathrm{H} 1 / 2}$ & $B_{\mathrm{cr}}$ & $B_{\mathrm{L} 1 / 2}$ & $B_{\mathrm{H} 1 / 2}$ & $B_{\mathrm{cr}}$ & $B_{\mathrm{L} 1 / 2}$ & $B_{\mathrm{H} 1 / 2}$ \\
\hline 1 & 502.9 & 79.4 & 794.3 & 403.8 & 56.2 & 501.2 & 547.3 & 199.5 & 707.9 \\
\hline 2 & 459.9 & 66.1 & 707.9 & 356.3 & 63.1 & 446.2 & 437.8 & 177.8 & 588.8 \\
\hline 3 & 426.3 & 66.1 & 707.9 & 349 & 50.1 & 446.2 & 450.7 & 125.9 & 588.8 \\
\hline 4 & 354.3 & 63.1 & 631 & 335.2 & 50.1 & 426.6 & 424.4 & 100 & 549.5 \\
\hline 5 & 241.2 & 31.6 & 398.1 & 334.1 & 39.8 & 354.8 & 418.2 & 100 & 537 \\
\hline 6 & 68.79 & 35.5 & 199.5 & 309.7 & 33.9 & 316.2 & 416.1 & 89.1 & 524.8 \\
\hline 7 & 95.35 & 20 & 125.9 & 293.7 & 15.8 & 263 & 414.5 & 63.1 & 398.1 \\
\hline 8 & 59.01 & & & 203.2 & 31.6 & 199.5 & 383.0 & 63.1 & 354.8 \\
\hline 9 & 61.9 & & & 104.7 & 20 & 182 & 381.0 & 50.1 & 398.1 \\
\hline 10 & 62.9 & & & 107.4 & & & 371.0 & 50.1 & \\
\hline 11 & 62.4 & & & 86.9 & & & 346.5 & & \\
\hline
\end{tabular}

${ }^{\mathrm{a}} B_{\mathrm{cr}}$ is the bulk remanent coercivity (in $\mathrm{mT}$ ) determined from back field demagnetization curves. $B_{\mathrm{H} 1 / 2}$ and $B_{\mathrm{L} 1 / 2}$ represent the coercivity of the magnetic 'hard' and 'soft' components, respectively (both in $\mathrm{mT}$ ), identified from IRM analysis. 
